\title{
Synergetic measurements of aerosols over São Paulo, Brazil using LIDAR, sunphotometer and satellite data during the dry season
}

\author{
E. Landulfo ${ }^{1}$, A. Papayannis ${ }^{2}$, P. Artaxo ${ }^{3}$, A. D. A. Castanho ${ }^{3}$, A. Z. de Freitas ${ }^{1}$, R. F. Souza ${ }^{1}$, N. D. Vieira Junior ${ }^{1}$, \\ M. P. M. P. Jorge ${ }^{4}$, O. R. Sánchez-Ccoyllo ${ }^{5}$, and D. S. Moreira ${ }^{5}$ \\ ${ }^{1}$ Instituto de Pesquisas Energéticas e Nucleares, São Paulo, Brazil \\ ${ }^{2}$ National Technical University of Athens, Athens, Greece \\ ${ }^{3}$ Instituto de Física da Universidade de São Paulo, São Paulo, Brazil \\ ${ }^{4}$ Instituto de Nacional de Pesquisas Espaciais, São José dos Campos, Brazil \\ ${ }^{5}$ Instituto de Geofísica, Astronomia e Ciências Atmosféricas da Universidade de São Paulo, São Paulo, Brazil
}

Received: 30 April 2003 - Published in Atmos. Chem. Phys. Discuss.: 2 June 2003

Revised: 16 September 2003 - Accepted: 17 September 2003 - Published: 29 September 2003

\begin{abstract}
A backscattering LIDAR system, the first of this kind in Brazil, has been set-up in a suburban area in the city of São Paulo $\left(23^{\circ} 33^{\prime} \mathrm{S}, 46^{\circ} 44^{\prime} \mathrm{W}\right)$ to provide the vertical profile of the aerosol backscatter coefficient at $532 \mathrm{~nm}$ up to an altitude of $4-6 \mathrm{~km}$ above sea level (asl). The measurements have been carried out during the second half of the so-called Brazilian dry season, September and October 2001 and during the first half of the dry season in August and September 2002. The LIDAR data are presented and analysed in synergy with aerosol optical thickness (AOT) measurements obtained by a CIMEL sun-tracking photometer in the visible spectral region and with satellite measurements obtained by the MODIS sensor. This synergetic approach has been used, not only to validate the LIDAR data, but also to derive a typical value ( $45 \mathrm{sr}$ ) of the so-called extinction-tobackscatter ratio (LIDAR ratio) during the dry season. The satellite data analysis offers additional information on the spatial distribution of aerosols over Brazil including the determination of aerosol source regions over the country. The LIDAR data were also used to retrieve the Planetary Boundary Layer (PBL) height, aerosol layering and the structure of the lower troposphere over the city of São Paulo. These first LIDAR measurements over the city of São Paulo during the dry season showed a significant variability of the AOT in the lower troposphere $(0.5-5 \mathrm{~km})$ at $532 \mathrm{~nm}$. It was also found that the aerosol load is maximized in the $1-3 \mathrm{~km}$ height region, although up to $3 \mathrm{~km}$ thick aerosol layers were also detected in the $2.5-5.5 \mathrm{~km}$ region in certain cases. Threedimensional 96-hours air mass back-trajectory analysis was also performed in selected cases to determine the source regions of aerosols around São Paulo during the dry season.
\end{abstract}

Correspondence to: E. Landulfo

(elandulf@net.ipen.br)

\section{Introduction}

Suspended aerosol particles play a significant role in Global Change issues, since they influence the earth's radiation balance and climate by scattering or absorbing both incoming and outgoing radiation and by acting as cloud condensation nuclei $(\mathrm{CCN})$. Tropospheric aerosols arise from natural sources, such as airborne dust, sea-spray and volcanoes and also from anthropogenic sources, such as combustion of fossil fuels and biomass burning activities and from gas-toparticles conversion processes (Pandis et al. 1995).

Air pollution in mega cities is one of the most important problems of our era. São Paulo is among the five largest metropolitan areas of the world, as well as one of the most populated with about 10 million inhabitants. Therefore, in all these mega-cities the human activities have an enormous impact on the air quality, as well as on their population health (Saldiva et al. 1995). Concerning the atmospheric quality, we highlight the suspended aerosol particles as a subject of continuous interest due the on-going expansion of the São Paulo metropolitan area, which carries more than 3.000 industries. Among them the main aerosol sources include heavy industries, such as iron and steel works, refineries, chemical manufacturing, cement, sulphuric acid, petrochemical plants and the automotive fleet, exceeding already 5 million vehicles.

Regarding its topography the city of São Paulo is located in a plateau at about 800 meters asl. And is surrounded by mountains of about $1200 \mathrm{~m}$ height. During the summer season the precipitation increases and many cold fronts generate meteorological instabilities, which indeed favour the pollution dispersion. These periods can extend over the autumn months of May and June, further on when the wintertime begins, a high-pressure semi-static regime over the São Paulo area is generally observed. This event becomes highly

(C) European Geosciences Union 2003 
favourable to air pollutants accumulation, especially during episodes of intense temperature inversions, occurring typically at $1000 \mathrm{~m}$ asl (Alonso et al. 1999).

In this study in addition to local urban pollution, we also searched for potential sources of biomass burning (pyrogenic) aerosols, due to clear forest activities in the Amazon basin and harvesting areas in neighbouring regions and also in the Northwest/Centre of Brazil during the dry season. These aerosols can be transported over the city of São Paulo, even from more remote areas, especially in the so-called winter months, when the biomass burning activities peak in central Brazil. Concerning their meteorological aspects the winter season in Brazil show two distinctive types of meteorological characteristics for the dry season, one which shows days with synoptic systems of low pressure associated with high wind speed and occasional rain, which are favorable to pollution dispersion, against days which are characterized by synoptic systems of high pressure that brought mostly sunny weather, low wind speed and a low height thermal inversion layer, in these conditions the pollution dispersion is rather unfavorable.

To study this biomass burning aerosols over the city of São Paulo we applied a strategy like the multi-platform campaign called INDOEX (Indian Ocean Experiment), which was organized to measure the long-range transport of air pollution from South and Southeast Asia toward the Indian Ocean during the dry monsoon season, where biomass burning activities are maximized (Lelieveld et al. 2001). In our study we employed a multi-instrument approach, using active and passive remote sensors, either ground- or space-based, namely a backscattering LIDAR system, a sun photometer and satellite data.

The LIDAR technique is based on the emission of a collimated laser beam in the atmosphere and on the detection of the backscattered laser light by the suspended atmospheric aerosols and atmospheric molecules. The LIDAR technique, through its high temporal (from seconds to minutes) and spatial $(3-15 \mathrm{~m})$ resolution, is a powerful tool to visualize in real time, the structure of the PBL using the aerosols as passive tracers of the atmospheric dynamic processes. A backscattering LIDAR can thus provide information on the PBL's mixed layer depth, entrainment zones and convective cells structure, aerosol distribution, clear air layering, cloud-top altitudes, cloud statistics, atmospheric transport processes and other inferences of air motion (Ferrare et al. 1991, Melfi et al. 1985, Crum et al. 1987, Balis et al. 2000, Papayannis and Chourdakis 2002).

The sun photometer data are used to provide AOT values at selected wavelengths and thus to derive the Angstroem Exponent values over S. Paulo. The synergy of CIMEL and LIDAR measurements also acts in minimizing the uncertainties of the assumptions made, especially when inverting the LIDAR signal, using the Klett's technique (Klett, 1985).

Aerosol optical thickness measurements performed with the sunphotometer were taken under "cloud free" conditions during the last period of the wintertime, September and October months in 2001, and in August and September 2002. The first set of CIMEL data are level 2, denominated as quality assured data (Holben et al, 1998, Smirnov et al., 2000), while those of 2002 are only cloud screened data, since the calibration procedure had not been applied yet, when this paper was prepared.

Some selected days were taken as case studies and for these days air mass backward trajectories were calculated using the University of São Paulo Back Trajectory Model (USPTM) (Freitas et al. 1996) in order to determine the height and origin of the aerosol load entering MASP.

For the purpose of identifying the origin of remote sources of aerosols we took the images from the Moderate Resolution Imaging Spectroradiometer (MODIS) aboard of the Terra Satellite.

\section{The Experimental Set-up and Methodology of Analy- sis}

The LIDAR system operated over the city of São Paulo is a coaxial mode single-wavelength backscatter system pointing vertically to the zenith. The light source is a commercial pulsed Nd:YAG laser operating at the second harmonic frequency $(532 \mathrm{~nm})$ with a fixed repetition rate of $20 \mathrm{~Hz}$. The average power can be selected as high as $3.3 \mathrm{~W}$ and the emitted laser beam has $7 \mathrm{~mm}$ diameter and a divergence of $0.5 \mathrm{mrad}$. The laser beam is sent to the atmosphere through a Newtonian telescope, which is equipped with a $30 \mathrm{~cm}$ receiving mirror and has a $1.3 \mathrm{~m}$ focal length. The optics set-up is such that the maximum overlap is reached at about $350 \mathrm{~m}$ above the LIDAR system (Chourdakis et al. 2002). The backscattered laser radiation is detected by a S20 photomultiplier (PMT) and a narrow band (1 nm FWHM) interference filter at $532 \mathrm{~nm}$ is used to select the desired wavelength and assure the efficient reduction of the background skylight during daytime operation, thus, improving the signal-to-noise ratio at $532 \mathrm{~nm}$. The PMT output signal is recorded in the analog mode by a 1-GSa/s digitising oscilloscope (DSO), having 11-bit resolution of analog-to-digital conversion (ADC). Data are averaged every 2 to $5 \mathrm{~min}$, with a typical spatial resolution of 15 to $30 \mathrm{~m}$.

As stated before, co-located CIMEL aerosol measurements were performed to determine the AOT values at several wavelengths in the visible spectrum and thus to enable the assessment of the $\mathrm{AE}$ values at the same spectral region. The principle of operation of the CIMEL instrument is to acquire aureole and sky radiances measurements. The standard measurements are taken $15 \mathrm{~min}$ apart, in order to allow for cloud contamination checking. These measurements are taken in the whole spectral interval, and their number depends on the daytime duration. The instrument precision and accuracy follow the standard Langley plot method within the standard employed by the AERONET network (Holben et al. 
1998). The CIMEL sun photometer is calibrated periodically by a remote computer or locally under the supervision of the AERONET network. The calibration methodology assures coefficient accuracy between 1 and 3\%, nonetheless various instrumental, calibration, atmospheric, and methodological factors influence the precision and accuracy of optical thickness and effectively the total uncertainty in the AOT retrieved values is less than $8 \%$ (Balis et al. 2000).

\subsection{LIDAR data retrieval}

In the present stage, the retrieval of the aerosol optical properties is based on the measurements of the aerosol backscatter coefficient $\left(\beta_{a e r}\right)$ at $532 \mathrm{~nm}$, up to an altitude of 5$6 \mathrm{~km}$ The determination of the vertical profile of the aerosol backscatter coefficient relies on the LIDAR inversion technique following the Klett's algorithm, as proposed by Klett (1985). One has however to bear in mind that this inversion technique is an ill-posed problem in the mathematical sense, leading to errors as large as 30\% when applied (Papayannis and Chourdakis, 2002). In general, the inversion of the LIDAR profile is based on the solution of the LIDAR equation, under the assumption of the single scattering approximation:

$$
\begin{aligned}
& P(\lambda, R)=P_{L}\left(\frac{c \tau}{2}\right) \beta(\lambda, R) A_{0} \xi(\lambda) \zeta R^{-2} \\
& \exp \left[-2 \int_{0}^{r} \alpha(\lambda, r) d r\right]
\end{aligned}
$$

Where, $P(\lambda, R)$ is the LIDAR signal received from a distance $R$ at the wavelength, $P_{L}$ is the emitted laser power, $A_{0}$ is the telescope receiving area, $\xi(\lambda)$ is the receiver's spectral transmission factor, $b(\lambda, R)$ is the atmospheric volume backscatter coefficient, $\zeta(R)$ is the overlap factor between the field of view of the telescope and the laser beam, $\alpha(\lambda, R)$ is the extinction coefficient, $c$ is the light speed and $\tau$ is the laser pulse length.

In this equation, the $\alpha$ and $\beta$ coefficients can be separated in two sets, one for the molecular scattering component and the other for the particle scattering component. Besides, in the Klett inversion technique, there is a reference altitude, $Z_{r e f}$, which is used as an upper limit, and has to be an aerosol-free region. Therefore, in this region and above it, the LIDAR signal shows a decay, which follows the molecular contribution only. This is regularly checked using the technique proposed by Chourdakis et al. (2002), which assures the perfect alignment of the LIDAR system.

As stated before, to retrieve the aerosol backscatter coefficient we applied the Klett's inversion technique assuming a "guessed" altitude-constant extinction-to-backscatter ratio (LR) in the lower troposphere. It is known that the LR depends on several parameters, such as the aerosol refractive index, the shape and size distribution of the aerosol particles. Besides, there is a strong dependence of LR on the temperature and humidity profiles in the atmosphere, that might

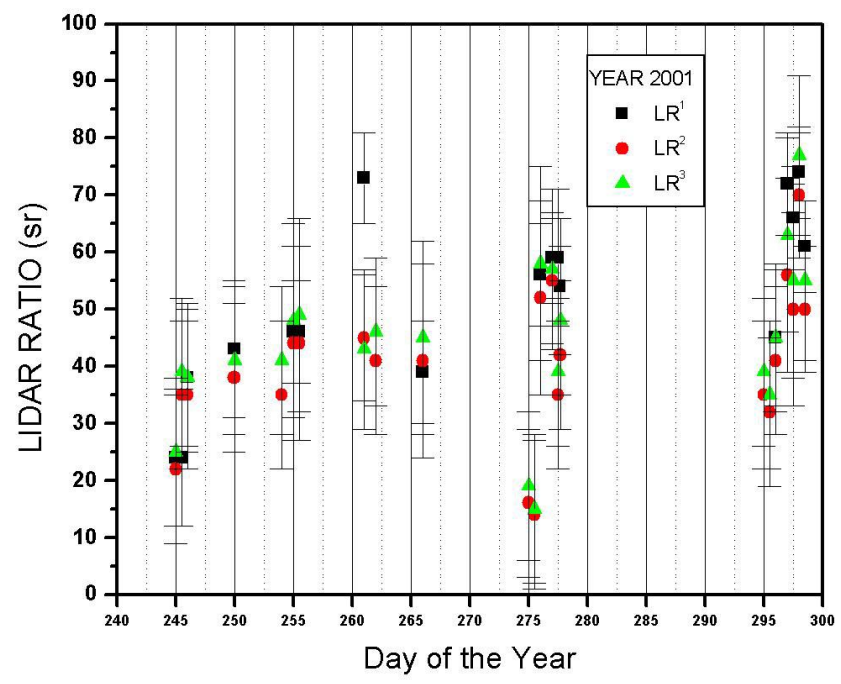

Fig. 1. The 2001 AOT's plotted versus the day of the year.

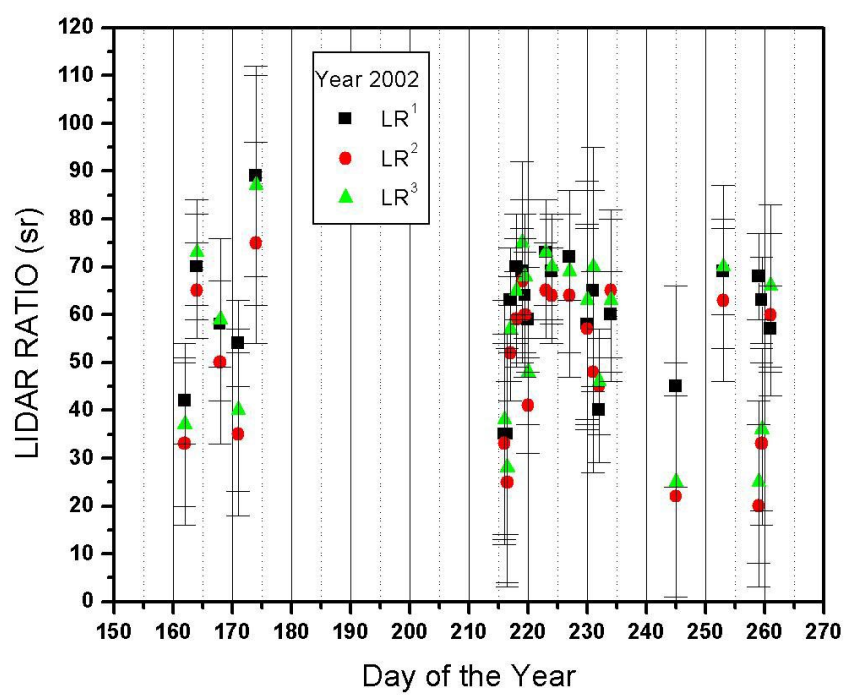

Fig. 2. The 2002 AOT's plotted versus the day of the year.

cause variations on the optical parameters of the aerosols (Haenel, 1976), and of course on the presence of turbulence in the atmospheric volume being probed by the LIDAR beam (Stull, 1991).

To derive the appropriate "correct" values of the vertical profile of aerosol backscatter coefficient in the lower troposphere we used an iterative inversion approach (by "tuning" the LR values) based on the inter-comparison of the AOT values derived by LIDAR and CIMEL data, assuming the absence of stratospheric aerosols and that the PBL is homogeneously mixed between ground and $300 \mathrm{~m}$ height, where the lidar overlap factor is close to 1 . Such a procedure is not novel (Chazette et al., 1995; Marenco et al., 1997). Once the "correct" values of the vertical profile of aerosol 
backscatter coefficient were derived (when the difference of the AOTs derived by CIMEL and LIDAR was less than 10\%) we reapplied the Klett method, using the appropriate LR values, to retrieve the final values of the vertical profiles of the backscatter and extinction coefficient at $532 \mathrm{~nm}$. The LR obtained from the CIMEL database was used as well, according to the following expression (Welton et al., 2002):

$S_{i}=\frac{4 \pi}{\omega_{0} P_{i}(180)}$

where $\omega_{0}$ is the Single Scattering Albedo and $P_{i}(180)$ is the backscaterring Phase Function.

\subsection{Sunphotometer Data Retrieval}

The inversion of the solar radiances measured by the CIMEL sunphotometer to retrieve the aerosol optical thickness values, is based on the Beer-Lambert equation, assuming that the contribution of multiple scattering within the small field of view of the sunphotometer is negligible:

$$
I_{\lambda}=I_{\lambda}^{0} \exp \left(-\frac{\tau_{\lambda}}{\mu_{S}}\right)
$$

Where, $I_{\text {lambda }}$ and $I_{\lambda}^{0}$ are the solar irradiances at the top of the atmosphere and at ground level, respectively, and $\mu_{S}$ is the cosine of the solar zenith angle. $\tau_{\lambda}$ is the total atmospheric optical thickness from the Rayleigh and aerosol contributions, as well the ozone and water vapour absorption at $670 \mathrm{~nm}$ and $870 \mathrm{~nm}$, respectively. The molecular (Rayleigh) scattering contribution is taken into account to retrieve the aerosol optical thickness values at $532 \mathrm{~nm}$, determined by the relation:

$$
\frac{\tau_{532}^{a e r}}{\tau_{500}^{a e r}}=\left(\frac{532}{500}\right)^{-0}
$$

Where, the Ångström exponent (Ångström, 1964) ${ }_{-a}^{0}$ was derived from the measured optical thickness in the blue and red channels ( $440 \mathrm{~nm}$ and $670 \mathrm{~nm}$ ):

$$
0=-\frac{\log \left(\frac{\tau_{440}^{a e r}}{\tau_{670}^{a e r}}\right)}{\log \left(\frac{440}{670}\right)}
$$

\subsection{The MODIS sensor}

The Moderate Resolution Imaging Spectroradiometer (MODIS) was launched in December 1999 on the polar orbiting Terra spacecraft and since February 2000 has been acquiring daily global data in 36 spectral bands from the visible to the thermal infrared ( 29 spectral bands with $1 \mathrm{~km}$, 5 spectral bands with $500 \mathrm{~m}$, and 2 with $250 \mathrm{~m}$ nadir pixel dimensions). The Terra satellite has on-board exterior orientation (position and attitude) measurement systems designed to enable the geolocation of MODIS data to approximately $150 \mathrm{~m}$ at nadir. A global network of ground

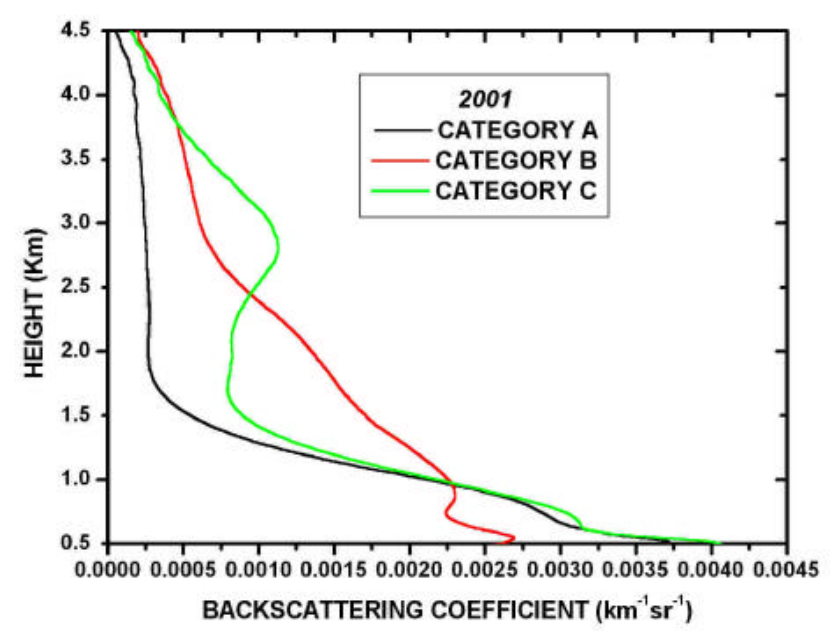

Fig. 3. Categories for comparison in the shape profile in year 2001 (winter season), the resolution used here is $15 \mathrm{~m}$.

control points is being used to determine biases and trends in the sensor orientation. Biases have been removed by updating models of the spacecraft and instrument orientation in the MODIS geolocation software several times since launch and have thus improved the MODIS geolocation to approximately $50 \mathrm{~m}$ at nadir. The Terra and Aqua spacecraft orbit the Earth at an altitude of $705 \mathrm{~km}$ in a near polar orbit with an inclination of $98.2^{\circ}$ and a mean period of $98.9 \mathrm{~min}$ (Salomonson et al., 1989). Terra's sun-synchronous orbit has a dayside equatorial 10:30 am local crossing time and a 16-day repeat cycle. MODIS has an $110^{\circ}$ across-track field of view and senses the entire equator every 2 days with full daily global coverage above approximately $30^{\circ}$ latitude (Wolf et al. 2002). MODIS is a paddle broom (sometimes called a whiskbroom) electro-optical instrument that uses the forward motion of the satellite to provide the along-track direction of scan. The electromagnetic radiation (EMR) reflected or emitted from the Earth is reflected into the instrument telescope by a rotating two-sided scan mirror. One-half revolution of the scan mirror takes approximately $1.477 \mathrm{~s}$ and produces the across-track scanning motion. The EMR is then focused onto separate calibrated radiation detectors covered by narrow spectral band-pass filters. MODIS simultaneously senses, in each band, 10 rows of $1 \mathrm{~km}$ detector pixels, 20 rows of $500 \mathrm{~m}$ detector pixels, and 40 rows of $250 \mathrm{~m}$ detector pixels. Each row corresponds to a single scan line of MODIS data that is nominally composed of 1354 ( $1 \mathrm{~km}$ detector pixels), 2708 (500 m detector pixels) and 5416 (250 $\mathrm{m}$ detector pixels) observations.

The MODIS AOD's retrieval followed the procedure given by Kaufman et al (1997), in these guidelines the AOD at $550 \mathrm{~nm}$ is given in $10 \mathrm{~km}$ resolution cloud screened, in Kaufman's article the algorithms given are matched for the multispectral reflectance observations in order to lookup the precomputed reflectance tables. 


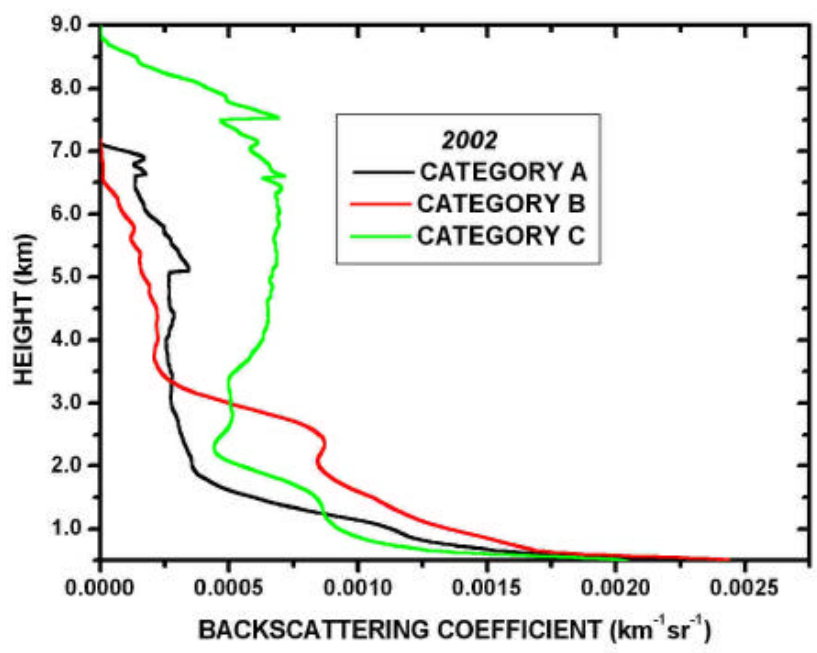

Fig. 4. Categories for comparison in the shape profile in year 2002 (winter season), the resolution applied here is $30 \mathrm{~m}$.

The aerosol optical thickness products over land are accurate to within their calculated uncertainties $\left( \pm 0.05 \pm 0.20^{*} \tau\right)$, except in situations with possible cloud contamination, over surfaces with sub pixel surface water such as coastal areas and marshes, and over surfaces with sub pixel snow or ice cover.

\subsection{3-D Backtrajectory Model}

The air mass backward trajectory calculations apply a 3dimensional (3-D) kinematic trajectory model, which was developed at the University of São Paulo (Freitas et al. 1996, Freitas et al. 2000). The air mass trajectories (called kinematic trajectories) are obtained using the three components of the wind field, which is numerically generated by the Regional Atmospheric Modelling System approach (RAMS) as shown by Pielke et al. (1992) and by Liston and Pielke (2001). The air parcel trajectory output is generated every $3 \mathrm{~min}$, thus providing the latitude, longitude and altitude coordinates. In this paper we show the trajectory locations every $6 \mathrm{~h}$ using a colour-coded scale. The model time period extends to about one week, while the corresponding spatial resolution is about $60 \mathrm{~km}$ (Freitas et al. 2000). In this paper we calculated 96-hours (4 days) back-trajectories of air masses ending over the city of São Paulo, in order to have a more realistic input about the origin of the air masses ending over our LIDAR site and to locate the aerosols sources near the São Paulo region.

\section{Experimental data - Dry Season Year 2001 and 2002}

The first LIDAR measurements started over São Paulo in August 2001. For the so-called dry season we selected some specific cloud-free days in the years 2001 and 2002, where
Table 1. Synergetic LIDAR and CIMEL measurements over São Paulo, during the dry season months of 2001 and 2002

\begin{tabular}{cc}
\hline Month and Year & $\begin{array}{c}\text { Number of days with } \\
\text { simultaneous CIMEL-LIDAR } \\
\text { observations }\end{array}$ \\
\hline September 2001 & 10 \\
October 2001 & 11 \\
June 2002 & 05 \\
August 2002 & 12 \\
September 2002 & 04 \\
\hline
\end{tabular}

CIMEL, lidar and satellite date were available and were typical for the aerosol loadings over the city of São Paulo. Table 1 summarizes the dates of simultaneous CIMEL and LIDAR measurements during the dry season months of the years 2001 and 2002. Also for the sake of comparison Figs. 1 and 2 show the Lidar Ratio (LR) distribution along the years of 2001 and 2002. In those figures the 3 methods for retrieving the LRs are also given. The first LR is the one retrieved directly from CIMEL, the second LR is the one used by LIDAR with $10 \%$ difference against the CIMEL and the last LR is the one applied to obtain a matching between the AOT's provided by CIMEL and LIDAR As previously mentioned the meteorological conditions during the dry season are favourable to air pollution increase over the city and usually are accompanied by the formation of a thermal inversion typically $1000-1200 \mathrm{~m}$ above ground level. Therefore, the majority of the aerosol load is trapped inside the PBL, which means between ground level and the top of the mixing layer (ML), typically $1 \mathrm{~km}$ above the ground. Figures 3 to 7 show some typical aerosol backscatter profiles obtained at $532 \mathrm{~nm}$ during selected days of the dry season period (Table 1). These profiles are sorted in three categories according to some common features of the vertical distribution of the aerosol backscatter coefficient in which the following characteristics are taken into account:

(a) Number of layers at various heights

Category A shows only one aerosol layer and above $1.5-2.0 \mathrm{~km}$ height the atmosphere is considered to be aerosol free $\left(\beta_{\text {aer }}\right.$ is less than $\left.0.005 \mathrm{~km}^{-1} \mathrm{sr}^{-1}\right)$, Category B shows more layers above $2.5-3.0 \mathrm{~km}$, and Category $\mathrm{C}$ show layers above $3.0 \mathrm{~km}$.

(b) Potential Sources of Aerosol Particles

In the profiles shown under Category A the aerosol load has probably originated in the neighborhood region of the LIDAR site. In the profiles shown under Category B local air pollution sources play the main role. Category $\mathrm{C}$ has a distinctive pattern from category $\mathrm{B}$ since its shape up to $2.0-2.5 \mathrm{~km}$ is very similar to Category A, which might be an indication the atmosphere above would be aerosol free, with the exception that a large 
Table 2. List of selected days measured in the dry seasons of years 2001 and the corresponding AOT, LR and Ångström Exponent values retrieved by sunphotometer (CIMEL) data

\begin{tabular}{|c|c|c|c|c|c|c|c|c|}
\hline Day $(\mathrm{mm} / \mathrm{dd})$ & Category & $\mathrm{LR}^{1}$ & $\mathrm{LR}^{2}$ & $\mathrm{LR}^{3}$ & $\mathrm{AOT}^{1}$ & $\mathrm{AOT}^{2}$ & $\mathrm{AOT}^{3}$ & Angs. Exp \\
\hline $09 / 03$ & B & $24 \pm 2$ & $22 \pm 3$ & $25 \pm 3$ & $0.26 \pm 0.02$ & $0.23 \pm 0.03$ & $0.25 \pm 0.03$ & $1.6 \pm 0.2$ \\
\hline $09 / 03$ & B & $24 \pm 3$ & $35 \pm 5$ & $39 \pm 5$ & $0.21 \pm 0.02$ & $0.19 \pm 0.03$ & $0.13 \pm 0.02$ & $1.7 \pm 0.3$ \\
\hline 09/04 & B & $38 \pm 4$ & $35 \pm 5$ & $38 \pm 5$ & $0.22 \pm 0.02$ & $0.20 \pm 0.03$ & $0.22 \pm 0.03$ & $1.8 \pm 0.3$ \\
\hline 09/08 & B & $43 \pm 4$ & $38 \pm 6$ & $41 \pm 5$ & $0.23 \pm 0.02$ & $0.20 \pm 0.03$ & $0.23 \pm 0.03$ & $1.8 \pm 0.2$ \\
\hline $09 / 12$ & B & N/A & $35 \pm 5$ & $41 \pm 5$ & $0.18 \pm 0.02$ & $0.15 \pm 0.02$ & N/A & $1.5 \pm 0.2$ \\
\hline $09 / 13$ & $\mathrm{C}$ & $46 \pm 5$ & $44 \pm 6$ & $48 \pm 6$ & $0.44 \pm 0.03$ & $0.40 \pm 0.05$ & $0.42 \pm 0.06$ & $1.6 \pm 0.2$ \\
\hline $09 / 13$ & $\mathrm{C}$ & $46 \pm 5$ & $44 \pm 6$ & $49 \pm 6$ & $0.41 \pm 0.03$ & $0.41 \pm 0.05$ & $0.38 \pm 0.06$ & $1.6 \pm 0.2$ \\
\hline 09/19 & A & $73 \pm 7$ & $45 \pm 6$ & $43 \pm 6$ & $0.15 \pm 0.02$ & $0.12 \pm 0.02$ & $0.25 \pm 0.03$ & $1.9 \pm 0.3$ \\
\hline $09 / 20$ & B & N/A & $41 \pm 5$ & $46 \pm 6$ & $0.14 \pm 0.02$ & $0.12 \pm 0.02$ & N/A & $1.7 \pm 0.2$ \\
\hline $09 / 24$ & $\mathrm{C}$ & $39 \pm 4$ & $41 \pm 5$ & $45 \pm 6$ & $0.35 \pm 0.03$ & $0.31 \pm 0.04$ & $0.29 \pm 0.04$ & $1.5 \pm 0.2$ \\
\hline $10 / 03$ & B & N/A & $16 \pm 2$ & $19 \pm 3$ & $0.05 \pm 0.01$ & $0.04 \pm 0.01$ & N/A & $1.6 \pm 0.2$ \\
\hline $10 / 03$ & B & N/A & $14 \pm 2$ & $15 \pm 3$ & $0.07 \pm 0.01$ & $0.06 \pm 0.02$ & N/A & $1.6 \pm 0.2$ \\
\hline $10 / 04$ & $\mathrm{C}$ & $56 \pm 6$ & $52 \pm 6$ & $58 \pm 7$ & $0.09 \pm 0.01$ & $0.07 \pm 0.02$ & $0.08 \pm 0.02$ & $1.9 \pm 0.3$ \\
\hline $10 / 05$ & A & $59 \pm 6$ & $55 \pm 7$ & $57 \pm 7$ & $0.18 \pm 0.02$ & $0.17 \pm 0.02$ & $0.19 \pm 0.03$ & $2.0 \pm 0.3$ \\
\hline $10 / 05$ & B & $59 \pm 6$ & $35 \pm 5$ & $39 \pm 5$ & $0.12 \pm 0.01$ & $0.11 \pm 0.02$ & $0.19 \pm 0.03$ & $2.0 \pm 0.2$ \\
\hline $10 / 05$ & B & $54 \pm 5$ & $42 \pm 6$ & $48 \pm 6$ & $0.13 \pm 0.01$ & $0.12 \pm 0.02$ & $0.16 \pm 0.03$ & $1.9 \pm 0.3$ \\
\hline $10 / 23$ & B & N/A & $35 \pm 5$ & $39 \pm 5$ & $0.14 \pm 0.01$ & $0.13 \pm 0.02$ & N/A & $1.3 \pm 0.2$ \\
\hline $10 / 23$ & B & N/A & $32 \pm 4$ & $35 \pm 5$ & $0.14 \pm 0.01$ & $0.13 \pm 0.02$ & N/A & $1.3 \pm 0.2$ \\
\hline $10 / 24$ & $\mathrm{~B}$ & $45 \mathrm{v} 4$ & $41 \pm 6$ & $45 \pm 6$ & $0.24 \pm 0.02$ & $0.22 \pm 0.03$ & $0.24 \pm 0.03$ & $1.5 \pm 0.3$ \\
\hline $10 / 25$ & $\mathrm{C}$ & $72 \pm 7$ & $56 \pm 7$ & $63 \pm 8$ & $0.21 \pm 0.01$ & $0.19 \pm 0.03$ & $0.24 \pm 0.03$ & $1.5 \pm 0.2$ \\
\hline $10 / 25$ & $\mathrm{C}$ & $66 \pm 7$ & $50 \pm 6$ & $55 \pm 7$ & $0.11 \pm 0.01$ & $0.10 \pm 0.02$ & $0.14 \pm 0.02$ & $1.4 \pm 0.2$ \\
\hline $10 / 26$ & A & $74 \pm 7$ & $70 \pm 9$ & $77 \pm 9$ & $0.28 \pm 0.02$ & $0.25 \pm 0.03$ & $0.27 \pm 0.03$ & $1.6 \pm 0.2$ \\
\hline $10 / 26$ & A & $61 \pm 6$ & $50 \pm 6$ & $55 \pm 6$ & $0.20 \pm 0.02$ & $0.18 \pm 0.03$ & $0.22 \pm 0.03$ & $1.6 \pm 0.2$ \\
\hline
\end{tabular}

Day: Days of the year 2001 the measurements were performed.

Category: Category for the Aerosol Profile.

$\mathrm{LR}^{1}$ : Lidar Ratio retrieved from CIMEL.

$\mathrm{LR}^{2}$ : Lidar Ratio used by LIDAR with th $10 \%$ approach.

$\mathrm{LR}^{3}$ : Lidar Ratio applied to obtain a matching between the AOT's provided by CIMEL and LIDAR.

AOT $^{1}$ : AOT provided by the CIMEL.

AOT $^{2}$ : AOT provided by the LIDAR.

AOT $^{3}$ : AOT provided by the LIDAR using the $\mathrm{LR}^{1}$.

layer in higher heights suggest that a long-range transportation might be occurring from remote areas outside the metropolitan area of São Paulo, which in cases of days 09/24/2001 and 08/23/2002 it is revealed by satellite and trajectory analysis that some of the aerosol load is coming from the outskirts of the Amazon Basin where biomass burning activities are taking place.

(c) Meteorology

The meteorology features for each category follows large scale parameters such as relative position of the anticyclone or cold front (Sánchez-Ccoyllo and Andrade, 2002): Category A days are characterized as South Atlantic Subtropical High days which are sunny preceded by rainy days where a wash out of pollutants occurred, with very little wind and a high temperature amplitude and visibility conditions are extremely good $(5-10 \mathrm{~km})$. Category B days are sampled as pre-frontal days distinguished by a series of days without rain with some scattered clouds, and the presence of some wind at ground level and higher altitudes, concerning visibility they are hazy therefore the conditions are not so good as in Category A. Category $\mathrm{C}$ days are tagged as postfrontal days which become very dry after sunrise and with very poor dispersion conditions, with some occurrences of thermal inversions, they are without clouds and with little wind as well at ground level.

\subsection{Profiles and Parameters for Category A days}

The mean aerosol backscatter profiles obtained for year 2001 (Fig. 3) and year 2002 (Fig. 4) show that the majority of the aerosol load in category A is confined between ground level and 1250-1750 $\mathrm{m}$ height. In these days the mixing layer did not evolve to higher heights and thus an "practically" aerosol free atmosphere is found above $2000 \mathrm{~m}$ height, expressed as a value of $\beta_{a e r} \leq 0.005 \mathrm{~km}^{-1} \mathrm{sr}^{-1}$ or less. In this context the 

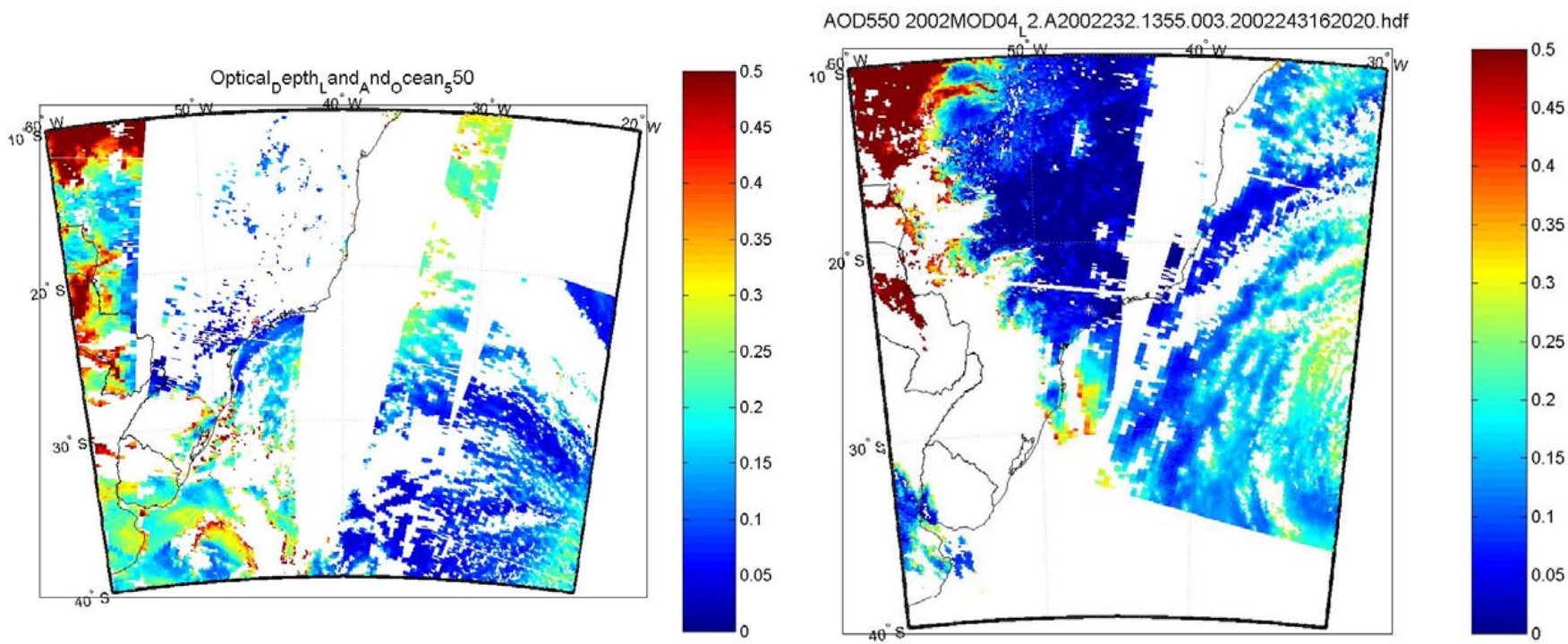

Fig. 5. MODIS AOT data exemplifying Category A days on 19 September 2001 and 20 August 2002 over São Paulo.
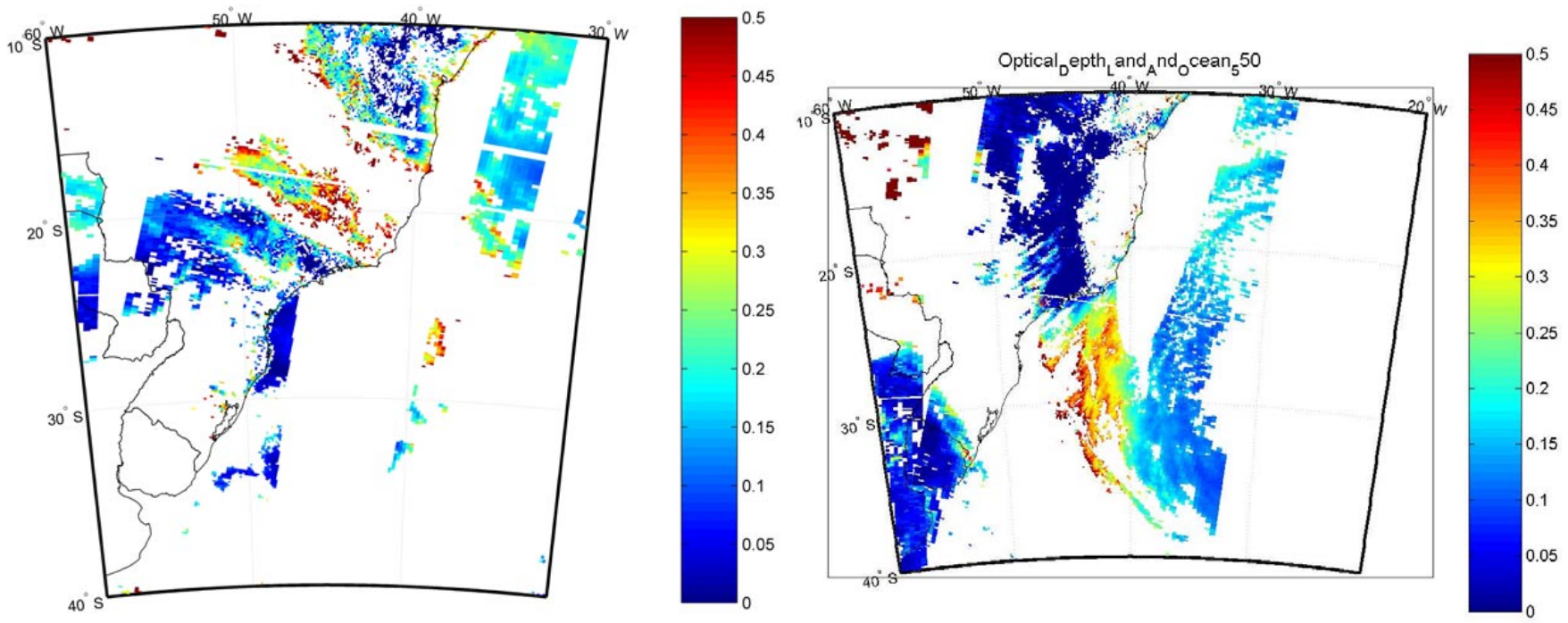

Fig. 6. MODIS AOT data exemplifying Category B days on 3 October 2001 and 21 August 2002 over São Paulo.

aerosol load observed inside the PBL should be due mainly to local urban activities, like car traffic, industrial emissions and other urban sources.

The AOT values obtained at $532 \mathrm{~nm}$ by the CIMEL during the year of 2001 (Table 2) show values ranging from 0,15 to 0,28 (average of 0,20 ), while the LIDAR values are generally $10 \%$ lower, due to the first $300 \mathrm{~m}$ not probed by the LIDAR system. As one applies the CIMEL retrieved LR's they are about $10 \%$ higher than the ones obtained by the LIDAR.

The LR's obtained through the three criteria are on average equal to 67,55 and $58 \mathrm{sr}$, the first LR is the one retrieved from CIMEL, the next LR is the one used by LIDAR with $10 \%$ difference in value and the last LR is applied to obtain a matching between the AOT's provided by CIMEL and LIDAR.

Similar values of the LR at $532 \mathrm{~nm}$ were reported by Mueller et al. (2001) and by Wandinger et al. (2002) for urban air polluted air masses during the INDOEX experiment. Their discrepancy might be related to the impossibility of having the same time-frame for the data acquisition, besides the figures obtained by the CIMEL oscillate more than $20 \%$ in value within few minutes of data acquisition, which 
Table 3. List of selected days measured in the dry seasons of years 2002 and the corresponding AOT, LR and ngstrm Exponent values retrieved by sunphotometer (CIMEL) data

\begin{tabular}{ccccccccc}
\hline Day(mm/dd) & Category & LR $^{1}$ & LR $^{2}$ & LR $^{3}$ & AOT $^{1}$ & AOT $^{2}$ & AOT $^{3}$ & Angs. Exp \\
\hline $06 / 12$ & C & $42 \pm 4$ & $33 \pm 4$ & $37 \pm 5$ & $0.17 \pm 0.02$ & $0.15 \pm 0.03$ & $0.19 \pm 0.03$ & $1.7 \pm 0.2$ \\
$06 / 14$ & B & $70 \pm 7$ & $65 \pm 7$ & $73 \pm 9$ & $0.23 \pm 0.02$ & $0.20 \pm 0.03$ & $0.22 \pm 0.03$ & $1.8 \pm 0.3$ \\
$06 / 18$ & C & $58 \pm 6$ & $50 \pm 5$ & $59 \pm 7$ & $0.06 \pm 0.02$ & $0.05 \pm 0.03$ & $0.06 \pm 0.03$ & $1.7 \pm 0.3$ \\
$06 / 21$ & C & $54 \pm 5$ & $35 \pm 4$ & $40 \pm 5$ & $0.11 \pm 0.02$ & $0.10 \pm 0.03$ & $0.15 \pm 0.03$ & $1.9 \pm 0.2$ \\
$06 / 24$ & A & $89 \pm 9$ & $75 \pm 9$ & $87 \pm 10$ & $0.19 \pm 0.02$ & $0.17 \pm 0.02$ & $0.20 \pm 0.02$ & $1.5 \pm 0.2$ \\
$08 / 05$ & A & $35 \pm 4$ & $33 \pm 4$ & $38 \pm 5$ & $0.13 \pm 0.03$ & $0.11 \pm 0.05$ & $0.12 \pm 0.02$ & $1.8 \pm 0.2$ \\
$08 / 05$ & A & $35 \pm 4$ & $25 \pm 3$ & $28 \pm 4$ & $0.10 \pm 0.03$ & $0.09 \pm 0.05$ & $0.12 \pm 0.02$ & $1.5 \pm 0.2$ \\
$08 / 06$ & B & $63 \pm 6$ & $52 \pm 6$ & $57 \pm 7$ & $0.22 \pm 0.03$ & $0.20 \pm 0.02$ & $0.24 \pm 0.02$ & $1.9 \pm 0.3$ \\
$08 / 07$ & B & $70 \pm 7$ & $59 \pm 7$ & $65 \pm 8$ & $0.20 \pm 0.02$ & $0.18 \pm 0.02$ & $0.22 \pm 0.02$ & $1.9 \pm 0.2$ \\
$08 / 08$ & $\mathrm{C}$ & $69 \pm 7$ & $67 \pm 8$ & $75 \pm 9$ & $0.20 \pm 0.02$ & $0.18 \pm 0.04$ & $0.19 \pm 0.04$ & $1.7 \pm 0.2$ \\
$08 / 08$ & $\mathrm{C}$ & $64 \pm 6$ & $60 \pm 8$ & $68 \pm 8$ & $0.18 \pm 0.03$ & $0.16 \pm 0.02$ & $0.17 \pm 0.02$ & $1.8 \pm 0.2$ \\
$08 / 09$ & $\mathrm{~B}$ & $59 \pm 6$ & $41 \pm 5$ & $48 \pm 6$ & $0.21 \pm 0.01$ & $0.18 \pm 0.02$ & $0.26 \pm 0.02$ & $1.7 \pm 0.2$ \\
$08 / 12$ & $\mathrm{~B}$ & $73 \pm 7$ & $65 \pm 8$ & $73 \pm 9$ & $0.29 \pm 0.03$ & $0.26 \pm 0.03$ & $0.29 \pm 0.03$ & $1.8 \pm 0.3$ \\
$08 / 13$ & $\mathrm{~B}$ & $69 \pm 7$ & $64 \pm 8$ & $70 \pm 9$ & $0.33 \pm 0.01$ & $0.30 \pm 0.04$ & $0.33 \pm 0.04$ & $1.8 \pm 0.3$ \\
$08 / 16$ & $\mathrm{C}$ & $72 \pm 7$ & $64 \pm 8$ & $69 \pm 8$ & $0.49 \pm 0.01$ & $0.45 \pm 0.06$ & $0.51 \pm 0.06$ & $1.7 \pm 0.2$ \\
$08 / 19$ & $\mathrm{~A}$ & $58 \pm 6$ & $57 \pm 7$ & $63 \pm 8$ & $0.12 \pm 0.02$ & $0.11 \pm 0.02$ & $0.11 \pm 0.02$ & $1.8 \pm 0.3$ \\
$08 / 20$ & $\mathrm{~A}$ & $65 \pm 7$ & $48 \pm 6$ & $70 \pm 9$ & $0.10 \pm 0.01$ & $0.09 \pm 0.02$ & $0.13 \pm 0.02$ & $1.8 \pm 0.2$ \\
$08 / 21$ & $\mathrm{~B}$ & $40 \pm 4$ & $45 \pm 4$ & $46 \pm 7$ & $0.15 \pm 0.02$ & $0.14 \pm 0.01$ & $0.12 \pm 0.02$ & $1.5 \pm 0.2$ \\
$08 / 23$ & $\mathrm{C}$ & $60 \pm 6$ & $65 \pm 8$ & $63 \pm 8$ & $0.30 \pm 0.03$ & $0.27 \pm 0.02$ & $0.29 \pm 0.02$ & $1.7 \pm 0.3$ \\
$09 / 03$ & $\mathrm{~A}$ & $45 \pm 5$ & $22 \pm 3$ & $25 \pm 4$ & $0.12 \pm 0.01$ & $0.11 \pm 0.01$ & $0.17 \pm 0.02$ & $1.7 \pm 0.2$ \\
$09 / 11$ & $\mathrm{C}$ & $69 \pm 7$ & $63 \pm 8$ & $70 \pm 9$ & $0.37 \pm 0.04$ & $0.33 \pm 0.02$ & $0.32 \pm 0.02$ & $1.7 \pm 0.2$ \\
$09 / 17$ & $\mathrm{C}$ & $68 \pm 7$ & $20 \pm 3$ & $25 \pm 3$ & $0.31 \pm 0.02$ & $0.27 \pm 0.03$ & $0.45 \pm 0.03$ & $1.8 \pm 0.2$ \\
$09 / 17$ & $\mathrm{C}$ & $63 \pm 6$ & $33 \pm 5$ & $36 \pm 5$ & $0.31 \pm 0.03$ & $0.28 \pm 0.01$ & $0.40 \pm 0.01$ & $1.6 \pm 0.2$ \\
$09 / 19$ & $\mathrm{C}$ & $57 \pm 6$ & $60 \pm 8$ & $66 \pm 8$ & $0.40 \pm 0.04$ & $0.36 \pm 0.02$ & $0.36 \pm 0.02$ & $1.7 \pm 0.3$ \\
\hline
\end{tabular}

Day: Days of the year 2002 the measurements were performed.

Category: Category for the Aerosol Profile.

$\mathrm{LR}^{1}$ : Lidar Ratio retrieved from CIMEL.

$\mathrm{LR}^{2}$ : Lidar Ratio used by LIDAR with th $10 \%$ approach.

$\mathrm{LR}^{3}$ : Lidar Ratio applied to obtain a matching between the AOT's provided by CIMEL and LIDAR.

AOT $^{1}$ : AOT provided by the CIMEL.

$\mathrm{AOT}^{2}$ : AOT provided by the LIDAR.

$\mathrm{AOT}^{3}$ : AOT provided by the LIDAR using the LR1.

might related to the high sensitivity of the CIMEL for the parameters used to obtain the LR, namely the Phase function and Single Scattering Albedo.

The Ångström exponent values calculated for this category were are 1.8 or higher, a value of ${ }_{a}^{0}$ above 1.6 is an indication of the presence of relatively bigger aerosols of urban origin (Deepak and Gerber 1983, D'Almeida et al. 1991), or even smaller particles like carbonaceous particles and of anthropogenic or biogenic sulphates that might haven swollen due humidity (Stull, 1991).

The 2002 AOT values obtained at $532 \mathrm{~nm}$ by the CIMEL in Table 3 show values ranging from 0,10 to 0,19 (average of 0,13 ), and slightly lower than those found in 2001. The LIDAR values again are $10 \%$ smaller than the values obtained by the CIMEL.

The LR's obtained in 2002 through the three mentioned criteria are on average equal to 55,43 and $52 \mathrm{sr}$. One point to stress is that in 2002 the LR values show a large interval of variation (25-75 sr for the LIDAR LRs) revealing a different sampling of aerosols present in the atmosphere on those days (Mishenko et al., 1997, Ackermann, 1998).

The ${ }_{a}^{0}$ values obtained in 2002 are in general from urban activities origin as the values of 1,7 and higher suggest with some days presenting slightly larger particles present in the atmosphere, such as dust and mineral aerosols. (Deepak and Gerber 1983, D'Almeida et al. 1991).

\subsection{Profiles and Parameters for Category B days}

The mean aerosol backscatter profiles representing Category B in 2001 (Fig. 3) and in 2002 (Fig. 4) show a different pattern from category $\mathrm{A}$, since one can observe higher and broader aerosol layers between 500 and $1500 \mathrm{~m}$ (2001), 1500 and $2500 \mathrm{~m} \mathrm{(2001)} \mathrm{and} 2000$ and $3500 \mathrm{~m}$ (2002) in altitude. Also at higher altitudes one can observe a discrete 

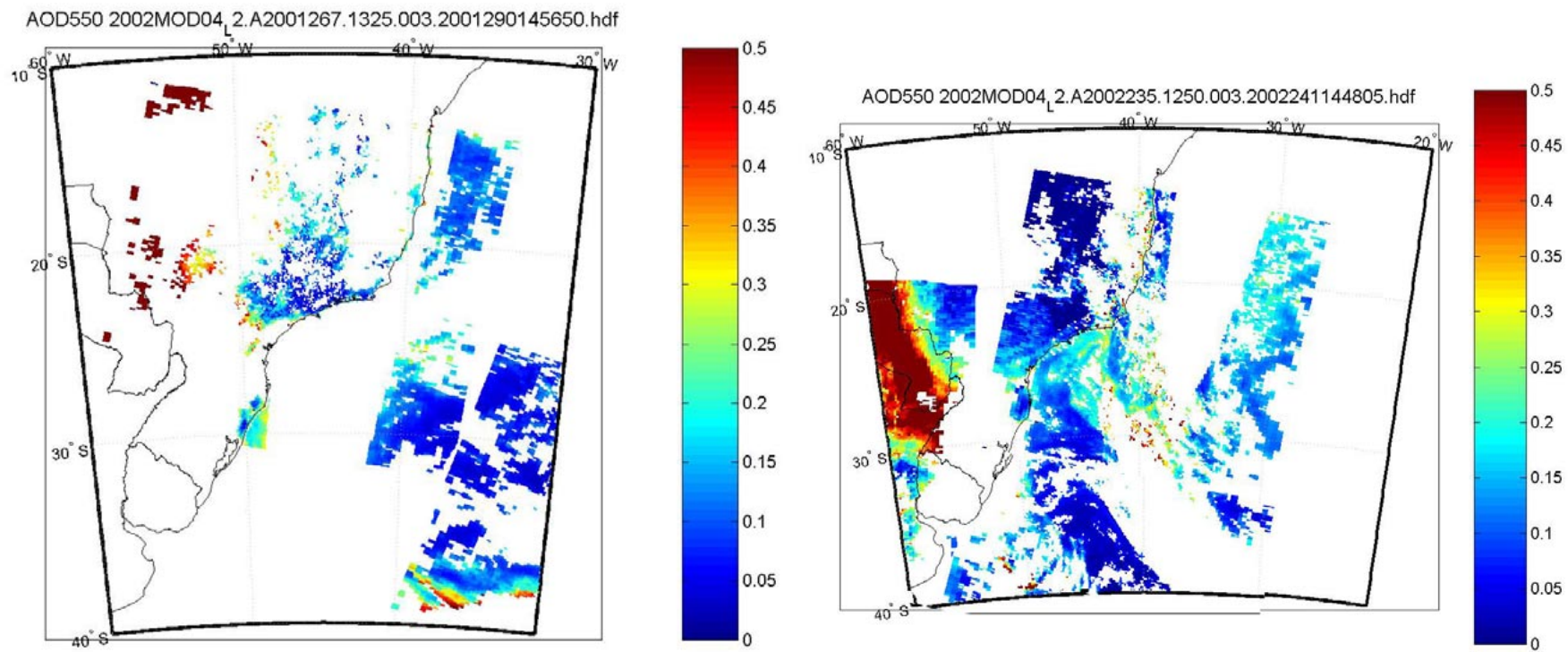

Fig. 7. MODIS AOT data exemplifying Category A days on 24 September 2001 and 23 August 2002 over São Paulo.
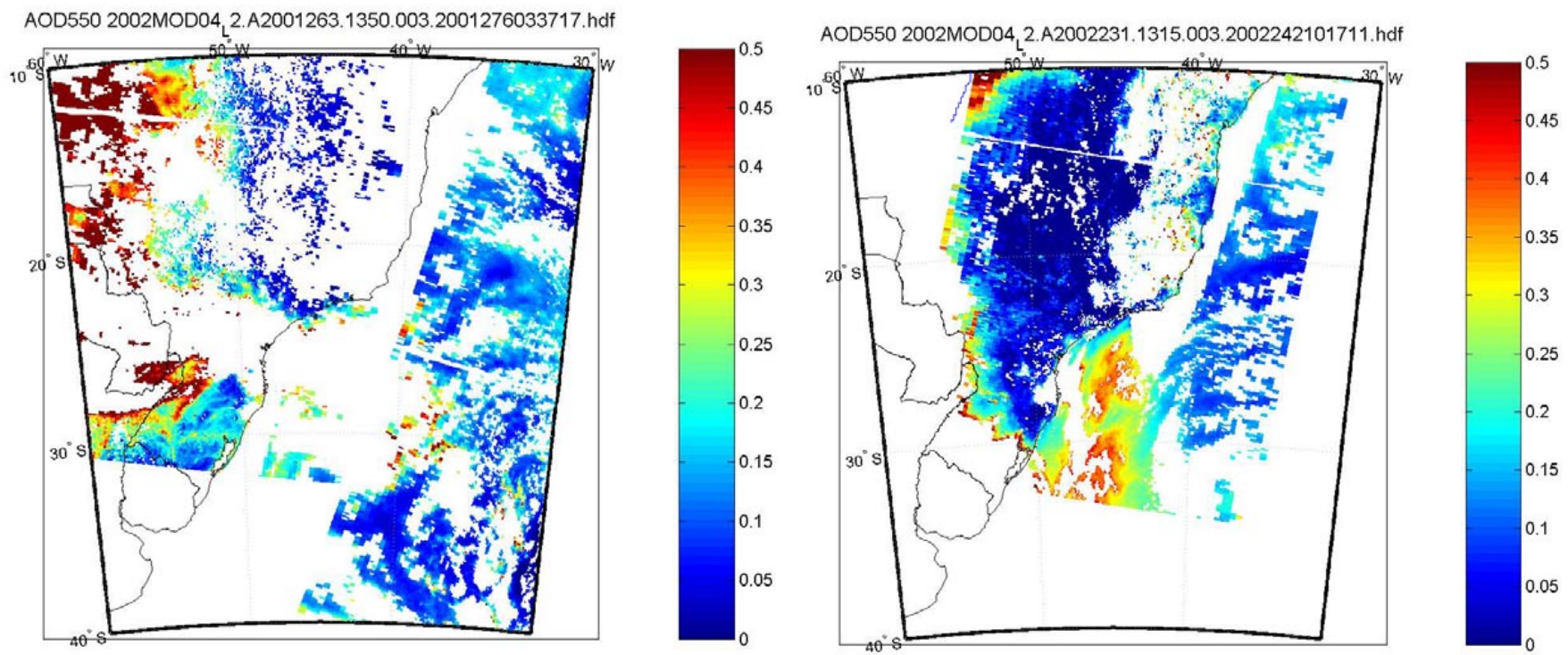

Fig. 8. MODIS AOT data on 20 September 2001 and 19 August 2002 over São Paulo, and the North-western region of Brazil where biomass burning activities were being carried on.

aerosol layer around $6000 \mathrm{~m}$ height. An aerosol "free" atmosphere is reached only above $4000 \mathrm{~m}$. concerning the potential aerosol sources one can still assume originating from the nearby regions mainly due to the urban activity concerning the first $1000 \mathrm{~m}$. The discrete aerosol layers found higher than $2500 \mathrm{~m}$ can be attributed to the residual layer from the previous day or most probably to particles originating from more remote areas.
The 2001 AOT values obtained at $532 \mathrm{~nm}$ by the CIMEL in Table 2 show values ranging from 0,05 to 0,26 (average of 0,16 ), about $20 \%$ less than in Category A, the LIDAR values still are $10 \%$ less as described before being attributed to the first $300 \mathrm{~m}$ not probed by the LIDAR system.

The LRs obtained through the three criteria are on average equal to 40, 33 and 36 sr. Compared to Category A, these values are considerably less, which might be related 

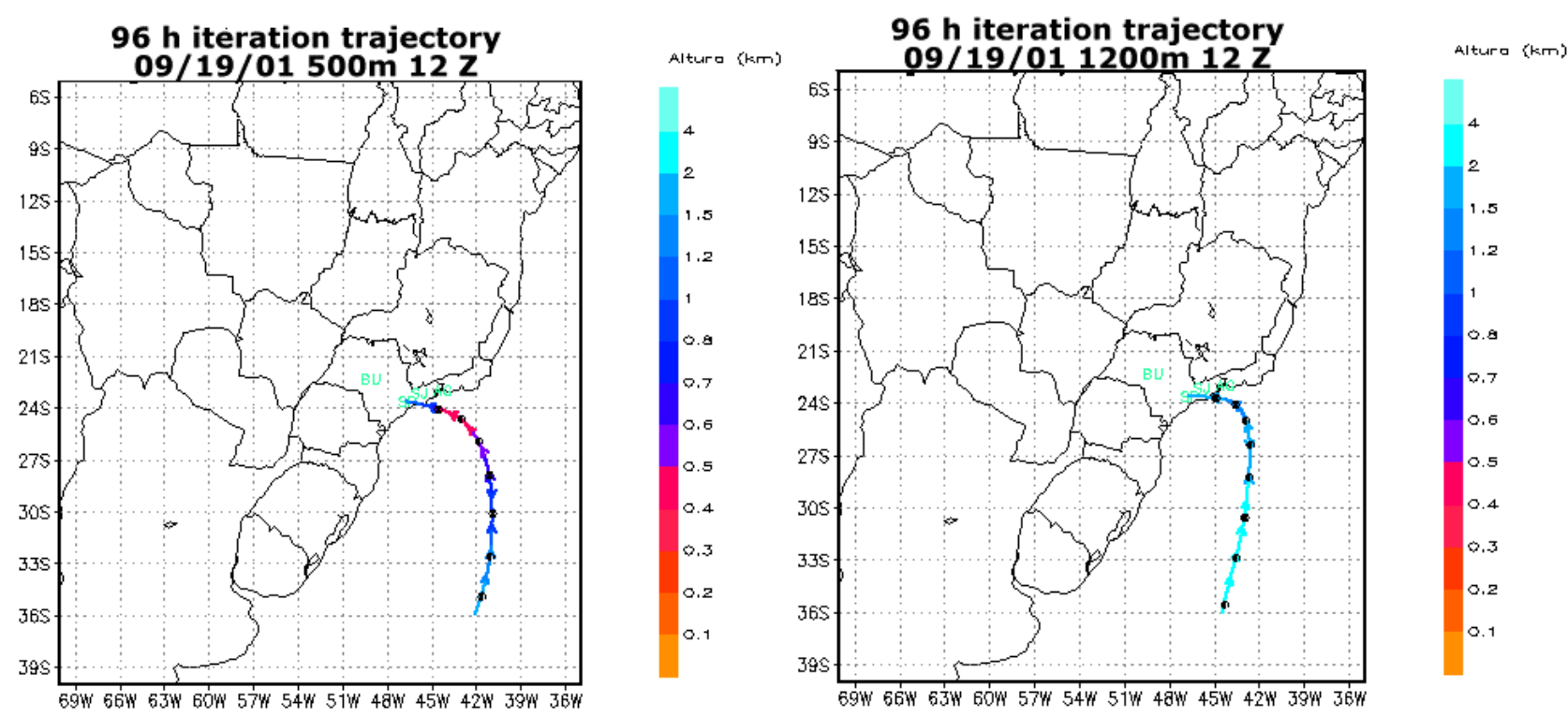

Fig. 9. 3-D 96-hours air mass back-trajectory analysis for air masses ending over São Paulo on 19 September 2001 at 12:00 GMT, at altitudes of $500 \mathrm{~m}$ and $1200 \mathrm{~m}$.

to the aerosol composition, with smaller particles in the atmosphere, however a more detailed study in this issue should be carried on.

The Ångström exponent values calculated for this category were are 1.6 or higher, a value of ${ }_{a}^{0}$ above 1.6 is an indication of the presence of rather small aerosols of urban origin, like carbonaceous particles and of anthropogenic or biogenic sulphates (Deepak and Gerber 1983, D'Almeida et al. 1991).

The 2002 AOT values obtained at $532 \mathrm{~nm}$ by the CIMEL (Table 3) show values ranging from 0,15 to 0,33 (average of $0,23)$, which are larger than the ones obtained in 2001. The LR's obtained by the three criteria are on average equal to 63 , 56 and $62 \mathrm{sr}$; again large individual values of LR were found (45-65) which would take part in values of AOT's as shown before.The Ångström exponent value of 1.8 indicates as well the presence of smaller particles in the atmosphere.

\subsection{Profiles and Parameters for Category $\mathrm{C}$ days}

The mean aerosol backscatter profiles belonging to Category C in 2001 (Fig. 3) and in 2002 (Fig. 4) show a very peculiar pattern distinctive from categories $\mathrm{A}$ and $\mathrm{B}$, since besides one the presence of a higher and broader aerosol layer above $1000 \mathrm{~m}$ up to about $2000 \mathrm{~m}$, there are also the presence of much higher layers at 2500 to $4000 \mathrm{~m}$ (2001), and 4000 to $7500 \mathrm{~m}$ (2002), therefore one can not only have the influence of not only endogenous sources of aerosols but also from exogenous sources, as the rural areas of intensive harvesting in the State of São Paulo and with more remote sources where biomass burning activities take place during this period of the year.
The 2001 AOT values obtained at $532 \mathrm{~nm}$ by the CIMEL in Table 2 show the highest individual values: $0.41(09 / 13)$ and $0.35(09 / 24)$, indicating that the aerosol column is affected by the presence of higher layers and thus reaching such high values of AOT. On average the AOT (0.27) is also larger than the ones in the previous categories. The LR's obtained through the three criteria are on average equal to 54,48 and $53 \mathrm{sr}$. These values are higher than in Category A, and comparable to those in Category B, however the variation between the maximum and minimum LR's is smaller than in other categories.

The average Ångström exponent value obtained in 2001 was 1.6 indicating the presence of rather small aerosol particles, such carbonaceous particles or even smoke aged aerosols diluted over the urban area of São Paulo coming from distant parts of the country (Eck et al. 1999). Looking individually through each day there was only one occurrence of an exponent higher than 1.6, $(1.9 \pm 0.3$, on 10/04) indicating the presence of rather smaller particles, such as carbonaceous particles and of anthropogenic or biogenic sulphates (Deepak and Gerber 1983, D'Almeida et al. 1991).

In 2002 AOT values obtained at $532 \mathrm{~nm}$ by the CIMEL in Table 3 show values as low as 0,06 (06/18) and as high as $0,49(08 / 16)$, if one inspect the LR individually for these days, it is clear that due their differences $-58(06 / 18)$ and 72 (08/16) - one might expect different aerosol compositions for each day.

The LR's obtained through the three criteria are on average equal to 61,50 and $55 \mathrm{sr}$. These values are again higher than in Category A, and comparable to those in Category B. These results are indicative of highly absorbing aerosol particles 

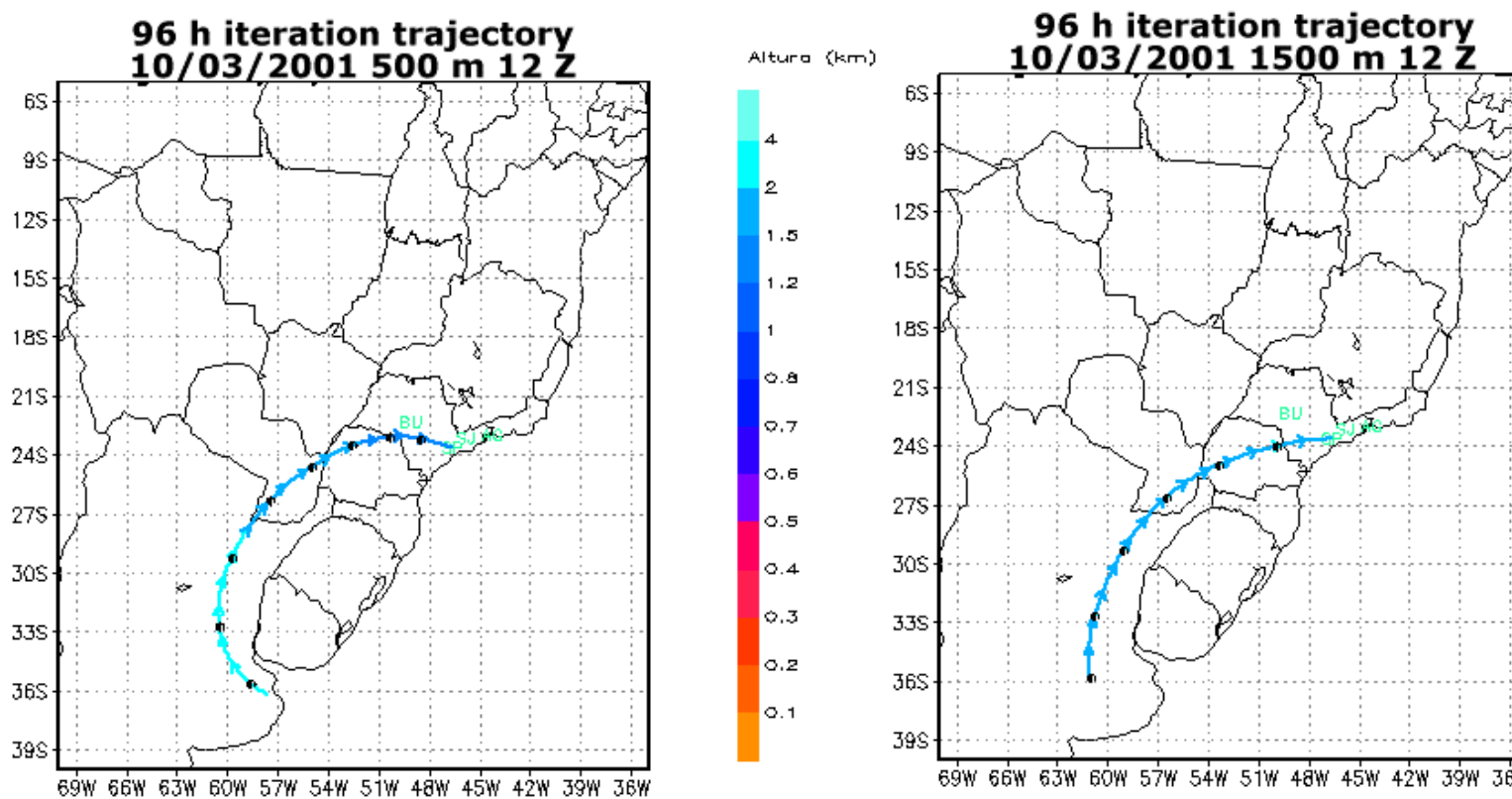

$96 \mathrm{~h}$ iteration trajectory
$10 / 03 / 20013500 \mathrm{~m} 12 \mathrm{Z}$
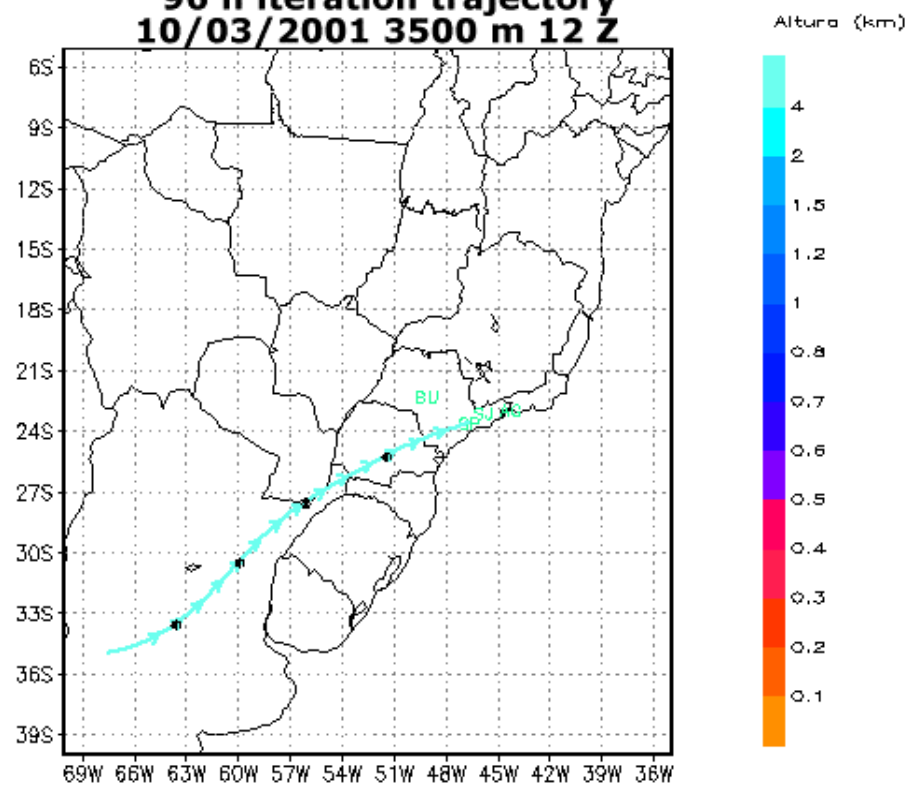

Fig. 10. 3-D 96-hours air mass back-trajectory analysis for air masses ending over São Paulo on 3 October 2001 at 12:00 GMT, at altitudes of $500 \mathrm{~m}, 1500 \mathrm{~m}$ and $3500 \mathrm{~m}$.

and are typical for biomass burning aerosols in the tropics, as shown by Mueller et al. (2001) during the INDOEX campaign and by Balis et al. (2003) during a large biomass burning event recently observed over Europe. The intense aerosol layers observed in general Category $\mathrm{C}$ files at altitudes higher than $2.5 \mathrm{~km}$ could be therefore attributed to long-range transported biomass burning aerosols. This could be verified by analysing the corresponding satellite data and by using air mass back-trajectory analysis.
The average Ångström exponent value obtained in 2002 was 1.7 indicating the presence of slightly smaller aerosol particles than the same category in the previous year, such carbonaceous particles or even smoke aged aerosols diluted over the urban area of São Paulo coming from distant parts of the country (Eck et al. 1999). 

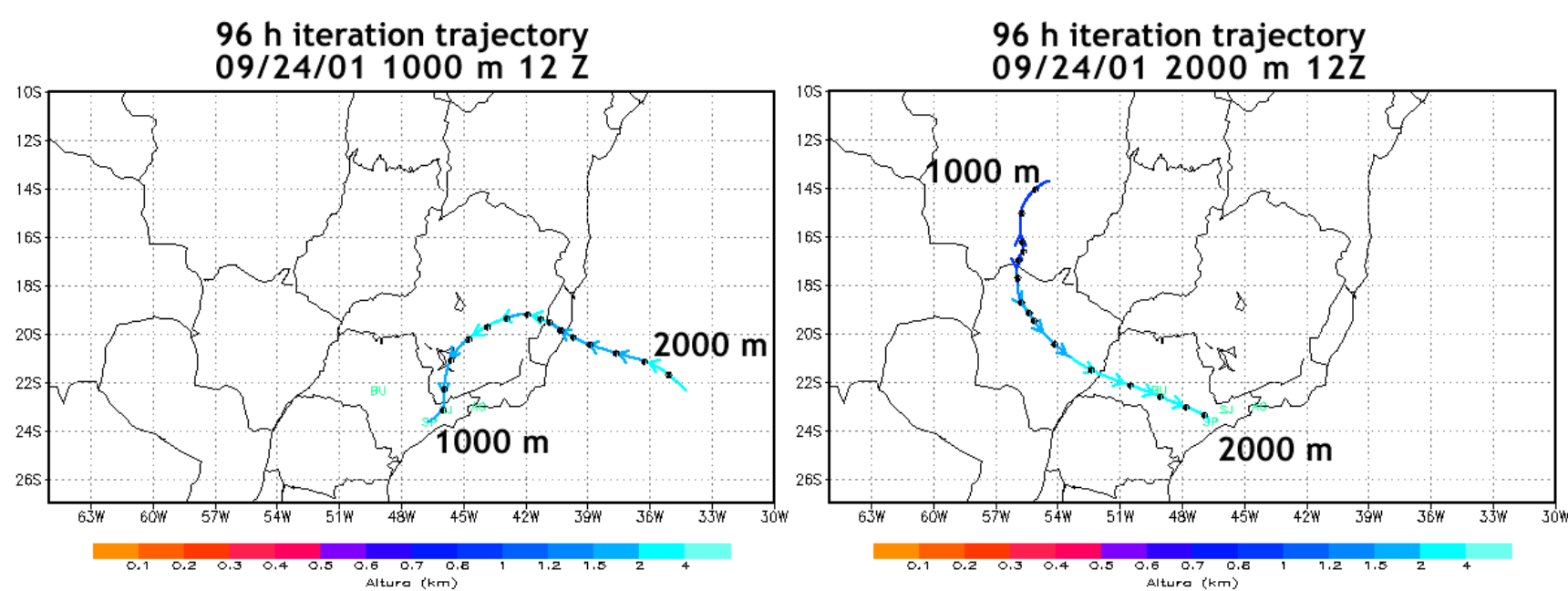

$96 \mathrm{~h}$ iteration trajectory 09/24/014500 m 12Z

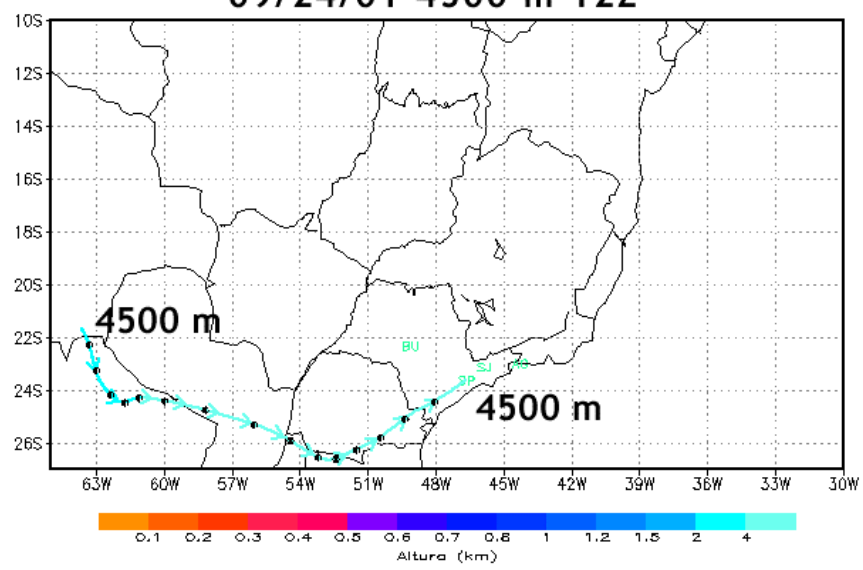

Fig. 11. 3-D 96-hours air mass back-trajectory analysis for air masses ending over São Paulo on 24 September 2001 at 12:00 GMT, at altitudes of $1000 \mathrm{~m}, 2000 \mathrm{~m}$ and $4500 \mathrm{~m}$.

\section{Satellite data and air mass back trajectory analysis}

To identify the source of high aerosol loadings observed over São Paulo region during the dry season we performed air mass back trajectory analysis with conjunction with satellite data derived from the MODIS sensor.

The MODIS AOT data over the São Paulo region are shown in groups of categories, in Fig. 5 we have Category A for days 19 September 2001 and 20 August 2002, in Fig. 6 are shown days pertaining to Category $\mathrm{B}$, namely 3 October 2001 and 21 August 2002, lastly Category C is depicted in Fig. 7 for days 24 September 2001, and 23 August 2002. For the days of Category A, 19 September 2001 and 20 August 2002, the AOT data obtained by MODIS show low (0.1) AOT values over São Paulo and higher AOT values $(0.35-0.5)$ west of the city, indicating the existence of a potential aerosol source. On the days of Category B, on 3 October 2001, the previous days were rainy due a cold front coming from the south of the continent which washed out the pollution, therefore the AOTs values are very low $(0.05-0.10)$, and were confirmed by the CIMEL data, while on 21 August 2002 the AOT values over São Paulo are similar to those retrieved by the CIMEL, which were of the order of $0.10-0.15$, in this instance again higher AOT values were found southeast of the city indicating the presence of advected aerosol particles $(0.2<\mathrm{AOT}<0.35)$ probably from the biomass burning or industrial regions inland. The MODIS AOT data for the days of Category $\mathrm{C}$ indicate AOT values over the city, in the order of $0.2-0.25$ for 24 September 2001 and of $0.15-0.20$ for 23 August 2002. One can also observe important AOT values $(0.30-0.50)$ west off the city of São Paulo, which could be due to biomass burning aerosols. Important AOT values $(0.15-0.30)$ were also observed south off the city on $23 \mathrm{Au}-$ gust 2002, which again could be advected biomass- burning aerosols. For identifying the sources of aerosols at higher altitudes in the Category $\mathrm{C}$ days we show in Fig. 8 the MODIS 


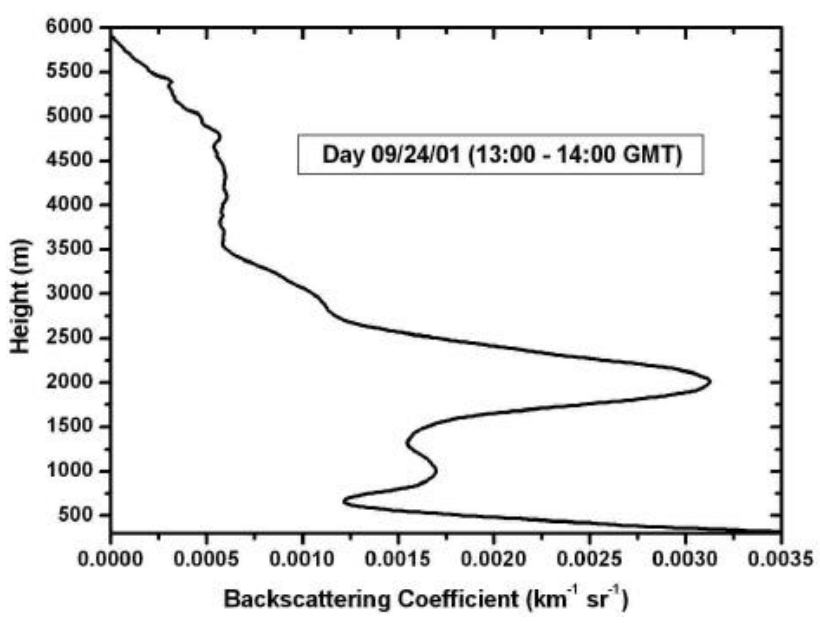

Fig. 12. Aerosol backscatter coefficient at $532 \mathrm{~nm}$ on 24 September 2001 (09:00-14:00 GMT).

plots for four previous days in advance of 20 September 2001 and 19 August 2002. It is noticeable in the northwest part of Brazil high levels of AOT due biomass burning activities being taken at those days, besides it is remarkable as well that biomass burning activities were occurring also on 20 August 2002 as seen in Fig. 5 (right-side panel).

We will focus now on the air mass trajectories ending at various heights over our LIDAR and CIMEL site during some sample days of Categories A, B and C. The air mass back trajectory plots are shown in an altitude-to-colour scale, and every interval between the white dots in the trajectories corresponds to a time step of 6 hours. Figure 9 display the backtrajectories for day 09/19/2001 (Category A) at heights 500 and $1200 \mathrm{~m}$, showing an air load originated at the Atlantic Ocean, one might expect them a maritime aerosol composition for this day.

The trajectories for day 10/03/01 are an example for a Category B day shown in Fig. 10, at heights 500, 1500 and $3500 \mathrm{~m}$, respectively. The aerosol loads are mainly southerly one coming from the North of Argentina, where industrial and rural activities are combined, so one might expect both types of aerosols together with those produced in São Paulo.

Category $\mathrm{C}$ days when the largest AOT values were measured are given in Figs. 11 and 13. On 24 September 2001 the altitudes chosen are at $1000 \mathrm{~m}, 2000 \mathrm{~m}$ and $4500 \mathrm{~m}$ above the LIDAR site, respectively. As shown in Fig. 11 the air masses ending at $1000 \mathrm{~m}$ height originated from the Atlantic Ocean around $2 \mathrm{~km}$ height, thus maritime aerosols should be predominant. On the other hand, the air masses ending at $2000 \mathrm{~m}$ height where an important aerosol layer observed in the LIDAR profile (Fig. 12) came from the northwestern direction and originated 4 days earlier at $1000 \mathrm{~m}$ height (on 20 September 2001) from a region where biomass burning is very common during the dry season. This indeed is verified by the MODIS data of that day (Fig. 8) where high
AOT values (0.35-0.5) were observed northwest of the city of São Paulo. The air masses ending at $4500 \mathrm{~m}$ had a completely different origin as they originated 4 days before from a southwestern direction, at the same altitude region, bringing probably continental biomass burning aerosols, which are observed as a $2 \mathrm{~km}$ thick aerosol layer between 3.5 and $5.5 \mathrm{~km}$ height. It is interesting to note that on 24 September 2001 the air masses ending over São Paulo at various heights up to $4500 \mathrm{~m}$ had completely different origins, thus carrying different types and sizes of aerosol particles (maritime, continental, urban and biomass burning aerosols).

On 23 August 2002 the 96-hours air mass back trajectories ending at $1000 \mathrm{~m}, 1900 \mathrm{~m}, 4000 \mathrm{~m}$ and $5400 \mathrm{~m}$ over São Paulo are shown in Fig. 13. At $1000 \mathrm{~m}$ and $1900 \mathrm{~m}$ end points we get air parcels from the north originating from the Atlantic Ocean, around 1900-2000 m height, and carrying mostly maritime aerosols. The MODIS AOT data for the previous days all indicated the advection of important aerosol loadings south of the city of São Paulo, as shown in Fig. 5 (right-panel), 6 (right-panel) and 8 (right-panel). This load could be related to advected biomass burning aerosols coming from the north-western part of the city, as shown by the back trajectory analysis for air masses ending at altitude levels between $4400 \mathrm{~m}$ and $5400 \mathrm{~m}$ and the corresponding MODIS AOT data on 19 August 2002 (Fig. 8), this is corroborated by the LIDAR profile given in Fig. 14 .

\section{Discussion and concluding remarks}

In this paper we presented synergetic measurements of aerosols over the São Paulo area, using lidar, sunphotometer and satellite data. The aerosol-backscattered profiles at $532 \mathrm{~nm}$ were obtained during the dry season of the years 2001 and 2002. Out of 51 vertical profiles of the aerosol backscatter coefficient we presented 5 selected profiles, which were sorted in three categories according to some common features of the vertical distribution of the aerosol backscatter coefficient.

The Klett inversion technique was applied in an iterative mode, with the synergy of the CIMEL data. Using this synergetic approach we derived a matched lidar ratio (LR) at $532 \mathrm{~nm}$ during each case of aerosol lidar profiles during the dry season. The mean value of LR found during the dry season was $45 \mathrm{sr}$, which is quite similar to the one found over urban areas during the INDOEX campaign by Mueller et al. 2001 and by Wandinger et al. 2002. One has of course to comment that the CIMEL data provides only the LR for the $440 \mathrm{~nm}$ wavelength and so the wavelength dependence here could be a critical parameter we might be overlooking. However, Mie-scattering computations done by Deirmendjian (Deirmendjian, 1969) show that the atmospheric volume backscattering coefficient does not change substantially in the $400-600 \mathrm{~nm}$ region. 

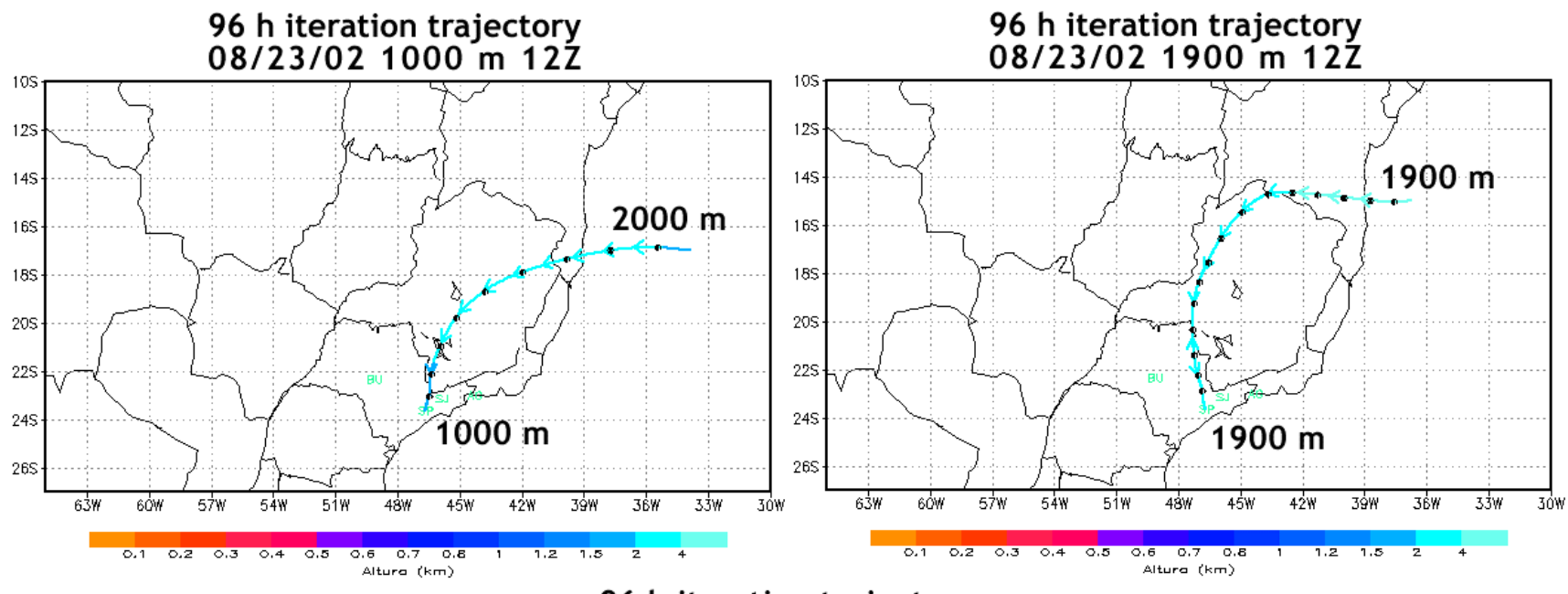

$96 \mathrm{~h}$ iteration trajectory

$08 / 23 / 024400 \mathrm{~m} 12 \mathrm{Z}$

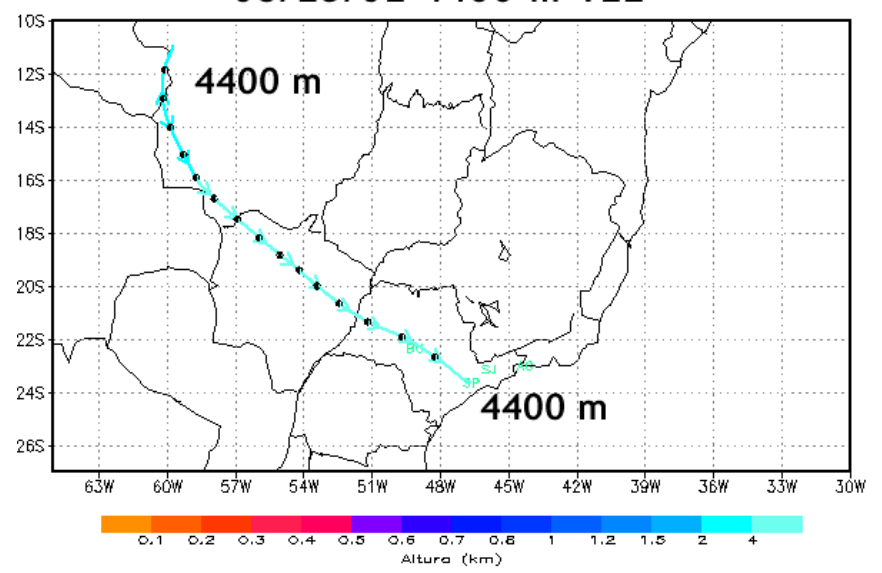

Fig. 13. 3-D 96-hours air mass back-trajectory analysis for air masses ending over São Paulo on 23 August 2002 at 12:00 GMT, at altitudes of $1000 \mathrm{~m}, 1900 \mathrm{~m}, 4400 \mathrm{~m}$ and $5400 \mathrm{~m}$.

Anyway, this issue should be indeed inspected in more details. Of course, a much larger number of aerosol backscatter profiles have to be collected over the São Paulo area, ideally with combination with a two-wavelength Raman lidar system (at 355 and $532 \mathrm{~nm}$ ) and the CIMEL sun photometer so that a typical value of the LR could be derived during the dry season.

Taking now into account all lidar measurements acquired during the dry season we made a category frequency histogram shown in Fig. 15. From this histogram one realizes that majority of days, namely 23 , are categorized as B, that means there are some layers mixed up to $3 \mathrm{~km}$, however their absolute value is close to an aerosol free atmosphere, this category represents $45 \%$ of all days. The second most frequent category is the A category, which is related to a low layer, up to $2 \mathrm{~km}$, and a very "clean" atmosphere higher up, this category is about $31 \%$ of all days, we have also seen that the A category examples we took are those with the lowest values of AOT, these days, in general follow a meteorological condition which favoured the dispersion of pollutants, either by rainy days, which washed out the atmosphere, or those preceding a cold front, which are in general windy days. Finally, there are the days related to the $\mathrm{C}$ category, which represent $24 \%$ of all days we took measurements, those days are, from the point of view of the origin of the air masses the most interesting since the air parcels probed over São Paulo were rich in long-range transported aerosols structured in distinct layers in the free troposphere and also they presented the highest AOT values. Observe that not all days which were categorized are shown in Table 1 and 2.

As a summary important aerosol loads were observed over the city of São Paulo, Brazil during the dry season, using a single-wavelength LIDAR system operating at $532 \mathrm{~nm}$ and a CIMEL automatic sun photometer. The LIDAR profiles revealed for the first time the existence of important quantities of aerosols at altitudes between 2500 and $5500 \mathrm{~m}$ above the 


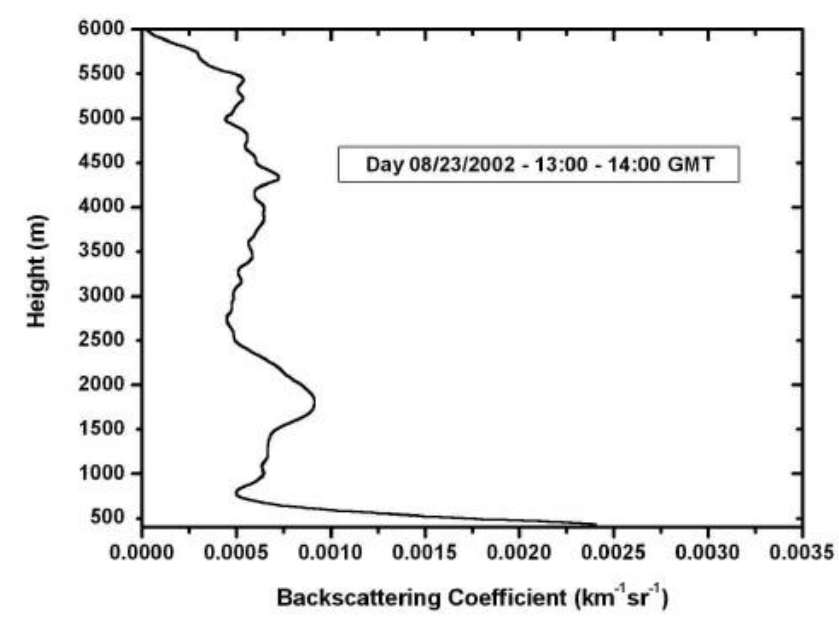

Fig. 14. Aerosol backscatter coefficient at $532 \mathrm{~nm}$ on 23 August 2002 (13:00-14:00 GMT).

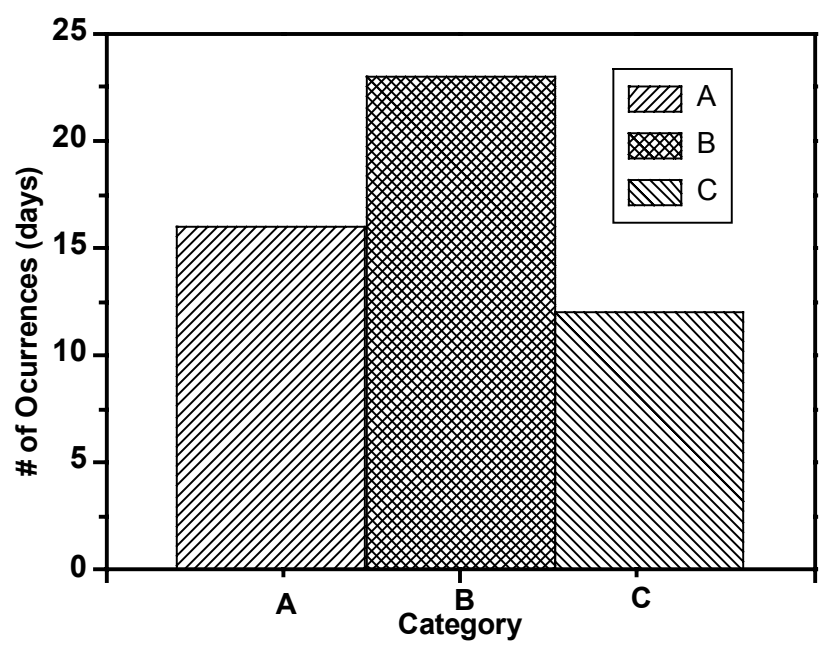

Fig. 15. Histrogram showing the frequency of Categories A, B and $\mathrm{C}$ for the LIDAR measurements.

LIDAR site, as well as in the altitude range between 1500 and $2000 \mathrm{~m}$ over the city of São Paulo. Three dimensional 96-hours air mass back-trajectory analysis showed that the aerosols detected at the higher altitudes may have originated from biomass burning activities taking place at the southern borders of the Amazon forest during the dry (fire) season. The MODIS AOT data confirmed the existence of biomass burning regions over the Amazon forest. The LIDAR profiles also showed the presence of aerosols at altitudes around 1500-2000 m, which corresponded to the upper part of the Planetary Boundary Layer over the city of São Paulo or originated over the Atlantic Ocean. These air masses are strongly influenced by local urban air pollution sources and are loaded with important quantities of anthropogenic aerosol particles. Additional measurements of the aerosol optical thickness us- ing a CIMEL sunphotometer, during the case studies analysed, showed increased values of AOT (0.2-0.5) mainly on 23 August 2002, related to long-range transported aerosols from biomass burning regions of the Amazon rain forest area. It is evident from the present study that biogenic and anthropogenic aerosols are responsible for the high aerosol loadings found in the upper part of the PBL and in the free troposphere over the city of São Paulo during the dry season. Considering the vast areas of tropical rain forests which are cleared every year by biomass burning activities in S. America and the high aerosol loads found in thus work during the dry season, biogenic and anthropogenic aerosol particles contribute in a major way to the AOT values observed and therefore these particles should play a very important role in the global aerosol budget.

It is also evident that the lidar aerosol profiles obtained over São Paulo during the dry season could provide an important input for radiative transfer models (RTM) and atmospheric chemistry transport models (ACTM) over S. America.

Acknowledgements. The authors would like to thank for the financial support given by the Federal Agency Conselho Nacional de Desenvolvimento Científico e Tecnológico (CNPq) and by the state of São Paulo agency Fundaão de Amparo à Pesquisa (FAPESP) under contract numbers 620009/98-5 and 98/14891-2, respectively. The AERONET network provided the CIMEL data and the MODIS data were provided by ESA-NASA. The MODIS data used in this study were acquired as part of the NASA's Earth Science Enterprise. The MODIS Science Teams developed the algorithms. The data were processed by the MODIS Adaptive Processing System (MODAPS) and Goddard Distributed Active Archive Centre (DAAC) and are archived and distributed by the Goddard DAAC.

\section{References}

Ackerman, J.: The extinction-to-backscatter ratio of tropospheric aerosol: A numerical study, J. Ocean. Atmos. Tech., 15, 10431050, 1998.

Alonso, C. D., and Romano, J.: São Paulo Metropolitan Area Air Quality Annual Report, São Paulo State Environmental Protection Agency - CETESB, 1-50, 1999.

Ångström, A.: The Parameters of Atmospheric Turbidity. Tellus, 16, 64-75, 1964.

Balis, D., Papayannis, A., Galani, E., Marenco, F., Santacesaria, V., Hamonou, E., Chazette, P., Ziomas, I., and Zerefos, C.: Tropospheric LIDAR aerosol measurements and sun photometric observations at Thessaloniki, Greece, Atmos. Environ., 34, 925932, 2000.

Balis, D., Amiridis, V., Zerefos, C., Gerasopoulos, E., Andreae, M., Zanis, P., Kazantzidis, A., Kazadzis, S., and Papayannis, A.: Raman lidar and sunphotometric measurements of aerosol optical properties over Thessaloniki, Greece during a biomass burning episode, submitted in Atmos. Environ., 2003.

Boesenberg, J.: EARLINET: A European Aerosol Research LIDAR Network, Adv. Laser Remote Sensing, Dabas, A., Loth, C., and Pelon, J. (Eds), 155-158, 2001. 
Chazette, P., David, C., Lefrere, J., Godin, S., Pelon, J., and G., Megie: Comparative Lidar Study of the optical geometrical, and dynamical properties of stratospheric post-volcanic aerosl, following the eruptions of El-Chinchon and Mount-Pinatubo, J. Geophys. Res. A, 100, D11, 23 195-23 207, 1995.

Chazette, P., Pelon, J., Dulac, F., Trouillet, V., Carrasco, I., and Hamonou, E.: Lidar evidence of desert dust layers in the Atlantic and Mediterranean and assessment of their infrared radiative impact, in Proceedings of the Nineteenth International Laser Radar Conference, Annapolis, USA, 6-10 July 1998, Singh, U. N. and Ismail, S. (Eds), 19-22, 1998.

Chourdakis, G., Papayannis, A., and Porteneuve, J.: Analysis of the receiver response for a non-coaxial LIDAR system with fiberoptic output, Appl. Opt., 41, 2715-2723, 2002.

Crum, T., Stull, R., and Eloranta, E.: Coincident LIDAR and aircraft observations of entrainment into thermal and mixed layers, J. Clim. Appl. Meteo., 26, 774-788, 1987.

D'almeida, G. A., Koepke, P., and Shettle, E. P.: IN: Atmospheric Aerosols, Global Climatology and Radiative Characteristics, Hampton, Virginia, 1991.

Deepak, A. and Gerber, H. E.: Aerosols and Their Climate Effects, Series Report 55, International Council of Scientific Unions and WMO, Switzerland, 1983.

Deirmendjian, D.: Electromagnetic Scattering on Spherical Polydispersions, American Elsevier, New York, 25-39, 1969.

Dubovik, O., Smirnov, A., Holben, B. N., King, M. D., Kaufman Y. J., Eck. T. F., and Slutsker, I.: Accuracy Assessments of Aerosol Optical Properties Retrieved From Aerosol Robotic Network (AERONET) Sun and Sky Radiance Measurements, J. Geophys. Res., 105, 9791-9806, 2000.

Eck, T. F., Holben, B. N., Reid, J. S., Dubovik, O., Smirnov, A., O'Neill, N. T., Slutsker, I., and Kinne, S.: Wavelenght dependence of the optical depth of biomass burning, urban, and desert dust aerosols, J. Geophys. Res., 104, 31 333-31 349, 1999.

Fernald, G. F.: Analysis of atmospheric LIDAR observations: some comments, Appl. Opt., 23, 652-653, 1984.

Ferrare, R., Schols, J., and Eloranta, E.: Lidar Observations of Banded Convection During BLX83, J. Appl. Meteor., 30, 312326, 1991.

Freitas, S. R., Longo, K. M., Silva Dias, M. A. F., and Artaxo, P.: Numerical Modeling of Air Mass Trajectories From the Biomass Burning Areas of the Amazon Basin, Ann. Acad. Bras. de Sci., (in Portuguese), 68 (Supplement 1), 1996.

Freiras, S. R., Silva Dias, M. A. F., Dias, P. L. S., Longo, K. M., Artaxo, P., Andreae, M. O., and Fischer, H. S.: A Convective Kinematic Trajectory Calculation for Low Resolution Atmospheric Models, J. Geophys. Res., 105, 375-386, 2000.

Haenel, G.: The properties of atmospheric aerosol particles in function of the relative humidity at themodynamic equilibrium with the scattering moist air, Adv. Geo., 19, 73-188, 1976.

Hamonou, E., Chazette, P., Balis, D., Dulac, F., Schneider, X., Galani, E., Ancellet, G., and Papayannis, A.: Characterization of the Vertical Structure of Saharan Dust Export to the Mediterranean Basin, J. Geophys. Res., 104, 22 257-22 270, 1999.

Holben, B. N., Eck, T. F., Slutsker, I., Tanré, D., Buis, J. P., Setzer, A., Vermote, E., Reagan, J. A., Kaufman, Y. J., Nakajima, T., Lavenu, F., Jankowiak, I., and Smirnov, A.: Aeronet - A Federal Instrument Network and Data Archive for Aerosol Characterization, Rem. Sens. Environ., 66, 1-16, 1998.
Junge, C. E.: Air Chemistry and Radioactivity, Academic Press Inc, New York, New York, 1963.

Klett, J.: Lidar inversion with variable backscatter/extinction ratios, Appl. Opt., 24, 1638-1643, 1985.

Lelieveld, J., Crutzen, P. J., Ramanathan, V., et al.: The Indian Ocean Experiment: Widespread air pollution from South and Southeast Asia, Science, 291, 1031-1036, 2001.

Liston, G. E. and Pielke, R.: A Climate Version of the Regional Atmospheric Modeling System, Theor. Appl. Climatol., 68, 155173, 2001.

Marenco, F., Santacesaria, V., Bais, A., Balis, D., di Sarra, D., Papayannis, A., and Zerefos C. S.: Optical properties of tropospheric aerosols determined by lidar and spectrophotometric measurements (PAUR campaign), Appl. Opt., 36, 6785-6886, 1997.

Measures, R.: Laser Remote Sensing: Fundamentals and Applications, Krieger Publ. Company, Florida, 45-89, 1992.

Melfi, S., Spinhirne, J., Chou, S.-C., and Palm, S.: LIDAR observations of vertically organized convection in the Planetary boundary Layer over the ocean, J. Clim. Appl. Meteor., 24, 806-821, 1985.

Mishchenko, M. I., Travis, L. D., Kahn, R. A., and West, R. A.: Modeling phase functions for dust-like tropospheric aerosols using a shape mixture of randomly oriented polydisperse spheroids, J. Geophys. Res., 102, 16 831-16847, 1997.

Mueller, D., Franke, K., Wagner, F., Althausen, D, Ansmann, A., Heintzenberg, J., and Verner, G.: Vertical profiling of optical and physical particle properties over the tropical Indian Ocean with six-wavelength lidar. 2, cases studies, J. Geophys. Res., 106, 28 577-28 595, 2001.

Pandis, S. N., Wexler A. S., and Seinfeld, J. H.: Dynamics of tropospheric aerosols, J. Phys. Chem., 99, 9646-9659, 1995.

Papayannis, A. and Chourdakis, G.: The EOLE Project. A Multiwavelength Laser Remote Sensing (LIDAR) System for Ozone and Aerosol Measurements in the Troposphere and the Lower Stratosphere, Part II: Aerosol Measurements over Athens, Greece, Int. J. Rem. Sens., 23, 179-196, 2002.

Pielke, R. A., Cotton W. R., Walko, R. L., Tremback C. J., Lyons, W. A., Grasso, L. D., Nicholls, M. E., Moran, M. D., Wesley, D. A., Lee T. J., and Copeland, J. H.: A Comprehensive Meteorological Modeling System - RAMS, Meteo. Atmos. Phys., 49, 69-91, 1992.

Salomonson, V., Barnes, W., Maymon, P., Montgomery H., and Ostrow, H.: MODIS - Advanced Facility Instrument for Studies of the Earth as a System, IEEE Trans. Geos. Rem. Sens., 27, 145$153,1989$.

Saldiva, P. H. N., Pope, C. A., Scharwtz, J., Dockery, D. W., Lichtnfels, A. J., Salge, J. M., Barone, I., and Bohm, G. M.: Air Pollution and Mortality in Elderly People: A Time-Series Study in São Paulo, Brazil, Arch. Environ. Health, 50, 159-163, 1999.

Smirnov, A., Holben, B. N., Eck, T. F., Dubovik, O., and Slutsker, I.: Cloud-Screening and Quality Control Algorithms for the AERONET Database, Remote. Sens. Environ., 73, 337-349, 2000.

Sánchez-Ccoyllo, O. R. and Andrade, M. F.: The influence of meteorological conditions on the bahaviour of pollutants concentrations in São Paulo. Environmental Pollution, 116, 257-263, 2002

Stull, R. B.: An Introduction to Boundary Layer Meteorology, 2nd edition, Boston, Kluwer Academic Publishers, 1-14, 1991. 
Wandinger, U., Mueller, D., Boeckmann, C., Althausen, D., Matthias, V., Boesenberg, J., Weib, B., Fiebig, M., Wendisch, M., Stohl., A., and Ansmann, A.: Optical and physical characterization of biomass burning and industrial pollution aerosols from multiwavelength lidar and aircraft measurements, J. Geophys. Res., 107, DOI 10.1029/2000, ID000202, 2002.

Welton, E. J., Voss, K. J., Quinn, P. K., Flatau, P. J., Markowicz, K., Campbell, J. R., Spinhirne, J. D., Gordon, H. R., and Johnson, J. E.: Measurements of Aerosol vertical profiles and optical properties during INDOEX 1999 using micropulse lidars, J. Geophys. Res., 107, D19,8019, 18-1-18-20, 2002.
Wolf, E. R., Nishihama, A. M., Fleig, A. A., Kuyper, A. J., Roy, A. D., Storey, B. J., and Patt, G. F.: Achieving sub-pixel geolocation accuracy in support of MODIS land science, Rem. Sens. Environ., 83, 31-49, 2002. 